\title{
Avaliação da associação entre índice de massa corporal e polimorfismos que codificam metaloproteinases da matriz, com cronologia de erupção dentária, em crianças manauaras
}

\author{
Tese de Doutorado apresentada à Faculdade de \\ Odontologia de Ribeirão Preto da Universidade de São \\ Paulo, como parte dos requisitos para obtenção do grau \\ de Doutor em Ciências. \\ Programa: Odontopediatria \\ Área de Concentração: Odontopediatria \\ Orientadora: Profa. Dra. Alexandra Mussolino de \\ Queiroz
}

Co-Orientadora: Profa Dra. Léa Assed Bezerra da Silva

\section{VERSÃO CORRIGIDA}




\section{AUTORI ZAÇÃo PARA RePRODUÇÃo}

Autorizo a reprodução e divulgação total ou parcial deste trabalho, por qualquer meio convencional ou eletrônico, para fins de estudo e pesquisa, desde que citada a fonte.

Evangelista, Silvane e Silva

Avaliação da associação entre índice de massa corporal e polimorfismos que codificam metaloproteinases da matriz, com cronologia de erupção dentária, em crianças manauaras.

87p. : il.; $30 \mathrm{~cm}$

Tese de Doutorado apresentada à Faculdade de Odontologia de Ribeirão Preto da Universidade de São Paulo, para obtenção do grau de Doutor em Ciências.Versão corrigida da Tese. A versão original se encontra disponível na Unidade que aloja o Programa.

Orientador: Queiroz, Alexandra Mussolino de

Co-orientador: Silva, Léa Assed Bezerra da

1. Criança; 2. Erupção Dentária; 3. Estado Nutricional; 4. Polimorfismo Genético. 


\section{FolHA de APROVAÇÃo}

Evangelista, SS. Avaliação da associação entre índice de massa corporal e polimorfismos que codificam metaloproteinases da matriz, com cronologia de erupção dentária, em crianças manauaras.

Tese de Doutorado apresentada à Faculdade de Odontologia de Ribeirão Preto da Universidade de São Paulo, como parte dos requisitos para obtenção do grau de Doutor em Ciências.

Programa: Odontopediatria

Área de Concentração: Odontopediatria

Aprovado em: / 2018

\section{BANCA EXAMI NADORA}

Prof.(a) Dr.(a)

Instituição:

J ulgamento: Assinatura:

\section{Prof.(a) Dr.(a)}

Instituição:

Julgamento: Assinatura:

\section{Prof.(a) Dr.(a)}

Instituição:

Julgamento: Assinatura:

Prof(a). Dr(a). Alexandra Mussolino de Queiroz - Orientadora e Presidente da Banca Examinadora

Assinatura: 



\section{Dados Curri culares}

\section{Si LVANE E SILVA EVANGELISTA}

Nascimento

Filiação

2000-2006

2005-2006

2006-2008

2008-2010
25 de outubro de 1982 - Fortaleza - CE

Sílvio Heleno do Amaral e Silva.

Maria Orlane do Nascimento e Silva.

Curso de Graduação em Odontologia.

Faculdade do Amazonas - IAES/AM

Iniciação Científica. Orientador: Prof. Dr. Emílio Sponchiado J únior. Faculdade do Amazonas-IAES

Curso de Especialização em Odontopediatria.

Universidade do Estado do Amazonas- UEA/AM.

Curso de Pós-Graduação em Saúde, Sociedade e Endemias na Amazonas, nível Mestrado.

Universidade Federal do Amazonas - UFAM/AM - Dissertação:

Bioativos Amazônicos: estudo etnobotânico e atividade antibacteriana de uma solução de limpeza de cavidades. Orientadora: Prof ${ }^{\text {a }}$ Dra. Maria Fulgência Costa Lima Bandeira.

2018-atualmente Docente nas disciplinas de Odontopediatria 1 e 2, Universidade Paulista-UNIP.

2016-2018

Curso de Pós-Graduação em Odontopediatria, nível Doutorado (DINTER) - tese: Avaliação da associação entre índice de massa corporal e polimorfismos que codificam metaloproteinases da matriz, com cronologia de erupção dentária, em crianças manauaras. Orientadora: Profa. Dra. Alexandra Mussolino de Queiroz. Co-orientadora: Prof ${ }^{a}$. Dra. Léa Assed Bezerra da Silva. Faculdade de Odontologia de Ribeirão Preto - USP. 



\section{DEDICATÓRIA}

A Deus maravilhoso, meu pai amado, que me guia e me protege em todos os momentos.

Aos meus pais, por me guiarem e acompanharem, por todos os valores que me transmitiram, pelos vossos sacrifícios e por tudo aquilo que me proporcionaram. Não há palavras para expressar o meu agradecimento, fizeram de mim o que sou hoje, e espero conseguir deixar-vos orgulhosos.

Meus filhos amados, André Luís e Bianca, razões do meu viver, esse sonho é por vocês, é para vocês. Obrigada pelo apoio na língua inglesa meu filho e pela paciência e amor nos momentos que estive ausente.

Meu marido querido André, pelo vosso amor incondicional e por me ensinar o que é amar. Por acreditar sempre, mesmo quando eu não acreditei. Por toda a tua ajuda, preocupação e apoio, e por nunca me deixar ir abaixo.

A minha irmã Helane pela torcida, incentivo e apoio em toda essa trajetória.

A minha irmã Simone por seu o meu exemplo profissional, dedicada e ética.

Aos meus sogros Jane e Isaías, sem vocês esse sonho não seria possível. Minha gratidão eterna.

Aos cunhados Adriana e Alexandre e demais familiares, o meu muito obrigada, por toda a força e todo o apoio. 



\section{Agradecimentos Especials}

A minha Orientadora, Profa. Dra. Alexandra Mussolino de Queiroz, agradeço a orientação, paciência e dedicação ao longo de todo este trabalho. Por seus ensinamentos e conselhos, sempre me mostrando a maneira correta de solucionar as intercorrências profissionais. Este trabalho foi finalizado com sucesso com a sua ajuda. A minha eterna gratidão e admiração.

À Profa Doutora Erika Calvano Küchler, com quem foram dados os primeiros passos deste projeto, pelos valores e pela sua ajuda. Por todo o rigor, sentido de responsabilidade e de trabalho que me incutiu, por elevar os meus conhecimentos, e pela frontalidade, otimismo, sinceridade, apoio, paciência e disponibilidade que sempre me disponibilizou. Se esforçou ao máximo para que tudo saísse como planejado, sempre me apoiando em todos os momentos e me aconselhando quando necessário. Despertou em mim o amor pela Biologia Molecular e me mostrou um mundo novo de conhecimentos. As palavras terminam mas a gratidão é eterna. 



\section{Agradecimentos}

À Universidade de São Paulo, nas pessoas do atual Reitor Prof. Dr. Vahan Agopyan, e do Vice-Diretor Prof. Dr. Antônio Carlos Hernandes.

À Faculdade de Odontologia de Ribeirão Preto da Universidade de São Paulo, na pessoa da Diretora, Profa. Dra. Léa Assed Bezerra da Silva, e do Vice-Diretor Prof. Arthur Belêm Novaes Jūnior.

À Coordenação do Curso de Pós-Graduação em Odontopediatria da Faculdade de Odontologia de Ribeirão Preto da Universidade de São Paulo, na pessoa da Coordenadora, Prof. Dra. Raquel Assed Bezerra Segato, e da Vice-Coordenadora, Profa. Dra. Lea Assed Bezerra da Silva.

A Universidade de São Paulo-USP e a Faculdade do Amazonas-IAES, por tornarem o meu sonho possível através de um doutorado Dinter inédito na Amazônia.

À Faculdade do Amazonas-IAES, na pessoa da Diretora Profa. Zobélia Maria de Souza Lopes e do coordenador Prof. Dr. Alberto Tadeu do Nascimento Borges.

A minha Co-Orientadora, Profa. Dra. Lea Assed Bezerra da Silva, a senhora é um grande exemplo de profissional. Reconhecida no mundo inteiro, foi um privilégio conhecê-la e me sinto honrada de tê-la como Co-Orientadora, sempre disposta a ajudar, fazendo muito além do papel de Professor. A minha eterna gratidão.

Aos Professores do Departamento de Clínica Infantil da FORP-USP, Prof. Dr. Alberto Consolaro, Prof. Dra. Léa Assed Bezerra da Silva, Prof. Dra. Raquel Assed Bezerra da Silva, Prof. Dra. Alexandra Mussolino de Queiroz, Prof. Dr. Paulo Nelson Filho, Prof. Dra. Aldevina Campos de Freitas, Prof. Dra. Andiara De Rossi Daldegan, Prof. Dr. Fabrício Kitazono de Carvalho, Prof. Dra. Kranya Victoria Díaz Serrano, Prof. Dra. Maria Cristina 
Borsatto, Prof. Dra. Maria da Conceição Pereira Saraiva, Prof. Dr. Fábio Lourenço Romano, Prof. Dr. José Tarcísio Lima Ferreira, Prof. Dra. Maria Bernadete Sasso Stuani, Prof. Dra. Mirian Aiko Nakane Matsumoto.

Ao Prof: Dr. Paulo Nelson-Filho, pela paciência, pelas correções e pelas aulas ministradas sempre com muita competência e amor. O senhor é para mim um exemplo de docente.

Ao Prof. Dr. Fabrício Kitazono de Carvalho, pelos conhecimentos compartilhados, pelo amor a odontopediatria, pela ajuda na elaboração do projeto de pesquisa para que esse sonho fosse possível, o meu muito obrigada. Desde a minha graduação o senhor é para mim um modelo a ser seguido.

Ao Professor Dr. Alexandre Vieira, da University of Pittsburgh, pelo apoio, incentivo e dedicação. Muito obrigada.

A Nilza Letícia Magalhães, pelo apoio no laboratório de genética com sua simpatia contagiante.

A Juliana Arrid, por ter sido uma colega muito presente e atenciosa em todos os momentos.

À Micheli Cristina Leite Rovanholo, pela assistência prestada e por esclarecer todas as minhas muitas dúvidas durante essa jornada.

Aos Funcionários do Departamento de Cínica Infantil, Filomena Leli Placciti, Matheus Morelli Zanela, Micheli Cristina Leite Rovanholo, Nilza Letícia Magalhães, Dra. Carolina Torres Montavani, Dr. Francisco Wanderley Garcia de Paula e Silva, Dra. Marilia Pacífico Lucisano, Carmo Euripedes Terra Barreto (in Memoriam), Marco Antônio dos Santos, Fátima Aparecida Jacinto Daniel, Fátima Aparecida Rizoli e Rosemary Alves, por todo o apoio oferecido no dia-a-dia e por sempre me tratarem com tanto amor, carinho e paciência. 
Aos Funcionários da FORP/USP, José Aparecido Neves do nascimento, Vera do Nascimento Scandelai, Karina Dadalt Quaglio, Gledson Antunes da Silva, Kleber Augusto Loureiro, Adriana de Mattos Gonçalves da Silva e Hermano Teixeira Machado, por todo o carinho e suporte durante todos estes anos. Muito Obrigada.

A Fundação de Amparo à Pesquisa do Estado de São Paulo/FAPESP, em nome da Profa Doutora Erika Calvano Küchler, pelo financiamento e incentivo a pesquisa (FAPESP 2015/06866-5).

Aos Meus Alunos de Graduação e meus pacientes, por serem um estímulo constante em busca do saber.

Aos Funcionários das Escolas, participantes da pesquisa, pela colaboração.

A todos as Crianças participantes da pesquisa, por tornarem este estudo possível.

Āos Alunos de Mestrado e Doutorado do Programa de Pós-graduação em Odontopediatria FORP/USP, pelo incentivo e apoio durante essa jornada.

A minha grande amiga Sidinéia Feitosa de Jesus, por ser um ser humano fantāstico, de coração tão puro e bom. Muito obrigada pelo apoio sempre.

Aos meus amigos e colegas de curso, pelo companheirismo durante esta jornada, pela humildade, partilha e interajuda, que prevaleceram frente aos maiores obstáculos. Em especial a minha dupla de todos os momentos nessa jornada, Kătia Regina Felizardo Vasconcelos que esteve presente em todos os momentos desta jornada tornando tudo um pouco mais "fácil", pois, dividindo as tarefas e obrigações unimos forças. A todos desejo os maiores sucessos e felicidades pela vida fora. 
Agradeço a todos que, de alguma forma, contribuíram para o meu crescimento pessoal e profissional.

A gratidão é a memória do coração!

Antîstenes de Atenas 


\section{EPÍGRAFE}

"Se o dinheiro for a sua esperança de independência, você jamais a terá. A única segurança verdadeira consiste numa reserva de sabedoria, de experiência e de competência."

(Henry Ford) 



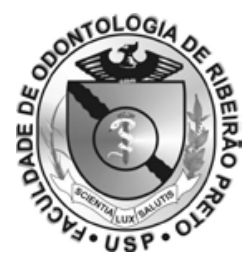

A Parte experimental desta Tese foi desenvolvida nos seguintes laboratórios:

- Laboratório de Biologia Molecular e Cultura de Células, do Departamento de Clínica Infantil da Faculdade de Odontologia de Ribeirão Preto - USP.

- Vieira Lab, do Departamento de Biologia Oral, Escola de Medicina Dentária, Universidade de Pittsburgh.

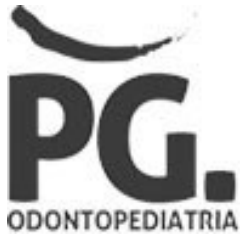





\section{RESUMO}

Evangelista, SS. Avaliação da associação entre índice de massa corporal e polimorfismos que codificam metaloproteinases da matriz, com cronologia de erupção dentária, em crianças manauaras. Ribeirão Preto, 2018. 87p. Tese [Doutorado]. Faculdade de Odontologia de Ribeirão Preto, Universidade de São Paulo.

Diversos mecanismos estão envolvidos no processo de erupção dentária. O objetivo deste estudo foi avaliar se o sobrepeso/obesidade e os polimorfismos genéticos nos genes que codificam as metaloproteinases da matriz (MMPs) - 8 e -13 estão associados com a cronologia de erupção dos dentes permanentes, em crianças de Manaus - AM. Um total de 216 crianças de escolas públicas foram incluídas, com idade variando entre 9 e 12 anos. Inicialmente foi aplicado um questionário, contendo dados anamnésicos relevantes para a pesquisa. Em seguida, o índice de massa corporal escore-z foi calculado, e as crianças foram divididas em 2 grupos: crianças com peso normal e crianças com sobrepeso/obesidade $(n=65)$. A seguir, foi efetuado o exame clínico, onde foram avaliados os dentes presentes na cavidade bucal e comparação com uma tabela de cronologia de erupção de dentes permanentes, sendo as crianças classificadas em 2 grupos: com atraso na cronologia de erupção e sem atraso na cronologia de erupção. Amostras de saliva de todos os participantes foram coletadas e utilizadas como fonte de DNA genômico. A genotipagem dos polimorfismos rs17099443 e rs3765620 em MMP8 e dos polimorfismos rs478927 e rs2252070 em MMP13 foi realizada pela análise do produto final de PCR, tecnologia Taqman. Os testes do qui-quadrado e/ou exato de Fisher foram utilizados para comparar crianças com e sem atraso de erupção. O grupo "sobrepeso / obeso" foi comparado com o grupo "peso normal" e comparado na proporção de 1:2. O teste de Shapiro-Wilk foi utilizado para verificar a normalidade dos dados. O teste t baseado na idade foi utilizado para comparação das médias entre os grupos. Uma análise de regressão linear usando idade e sexo como covariantes foi utilizada. O teste Anova com pós-teste de Tukey foi utilizado para comparar o número de dentes com atraso de erupção de acordo com o genótipo. 0 nível de significância adotado foi de $5 \%$. Cento e vinte e sete crianças foram classificadas com peso normal e 65 foram classificadas com sobrepeso/obesidade (49 com sobrepeso e 16 com obesidade). A condição de sobrepeso/obesidade associouse ao sexo, no qual os meninos tiveram maior chance de apresentar condições de maior peso ( $O R=1,84 ;$ IC $95 \% 1,06-3,37 ; p=0,04)$. O número médio de dentes permanentes irrompidos foi maior no grupo sobrepeso/obesidade $(p<0,001)$. A análise de regressão linear demonstrou que o estado nutricional, sexo e idade estavam fortemente associados ao número de dentes permanentes irrompidos $(p<0,05)$. Concluiu-se que crianças manauaras com sobrepeso/obesidade apresentam aceleração da cronologia de erupção dentária, quando comparadas com crianças com peso normal. Não houve associação do gene MMP13 com atraso na cronologia de erupção e verificou-se que o polimorfismo rs17099443 em MMP8 está associado com atraso de erupção dentária, onde o genótipo GG e o alelo G foram encontrados mais frequentemente nas crianças com atraso da cronologia de erupção. Crianças com o genótipo GG nesse polimorfismo apresentavam um maior número de dentes permanentes com atraso na cronologia de erupção do que as crianças com os genótipos CC e CG.

Palavras-chave: Criança; Erupção Dentária; Estado Nutricional; Polimorfismo Genético. 



\begin{abstract}
Evangelista, SS. Evaluation of the association between body mass index and polymorphisms in genes that codify matrix metalloproteinases with tooth eruption chronology in children from Manaus. Ribeirão Preto, 2018. 87p. Thesis [Doctorate]. Ribeirão Preto Dental school, São Paulo University.
\end{abstract}

Many mechanisms are involved in the in the tooth eruption process. The aim of this study was to evaluate if overweight/obesity and genetic polymorphisms in genes that codify the matrix metalloproteinases (MMPs) - 8 and - 13 are associated with permanent tooth eruption chronology, in children from Manaus-AM. A total of 216 children from public were included, with the age ranging from 9 to 12 years old. Initially, a questionnaire was used containing anamnesic data relevant to the research. Body mass index z-score was calculated and the children were separated in two groups: normal weight children $(n=127)$ and overweight/obesity children $(n=65)$. The clinical examination was performed, the number of permanent teeth erupted in the oral cavity were evaluated and compared with a table of permanent tooth eruption chronology, in which the children were classified in two groups: with $(n=126)$ and without delayed tooth eruption $(n=90)$. Saliva samples were collected from all samples as a genomic DNA source. The genotyping of the polymorphisms rs17099443 and rs3765620 in MMP8, and of the polymorphisms rs478927 and rs2252070 in MMP13 were performed in the end-point analysis of the real time PCR, Taqman technology. Chi-square and/or Fisher exact tests were used to compare children with and without delayed tooth eruption. The "overweight/obesity" group was compared with "normal weight" group in the ratio 1:2. The Shapiro-Wilk test was used to verify the normality of the data. The t test was used based on the age was used to compare the means between groups. A linear regression analysis using age and gender and gender as co-variants was performed. Anova with Tukey posttest was used to compare the number of delayed tooth eruption according to the genotype. The significance level adopted was 5\%. One hundred twenty-seven children were classified as normal weight and 65 as overweight/obesity (49 with overweight and 16 with obesity). Overweight/obesity condition was associated with gender, in which boys had a higher chance to present the condition (OR $=1.84$; IC 95\% 1.06-3.37; $p=0.04)$. The mean number of erupted permanent teeth was higher in the group overweight/obesity $(p<0.001)$. The linear regression analysis demonstrated that the nutritional status, sex and age were associated with the number of erupted permanent teeth $(p<0.05)$. In conclusion, children from Manaus with overweight/obesity presented an acceleration in the chronology of tooth eruption process in comparison with the normal weight children. The polymorphism rs17099443 in MMP8 is associated with delayed tooth eruption, and the genotype GG and the $\mathrm{G}$ allele were more frequent in the children with delayed on the chronology of tooth eruption. Children with GG genotype presented a higher number of permanent teeth with delayed on the chronology of tooth eruption than children with the genotypes CC and CG.

Key-word: Children; Tooth Eruption; Nutritional Status; Genetic Polymorphism. 



\section{SUMÁRIO}

1. INTRODUÇÃO.

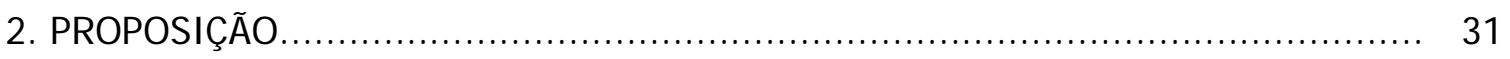

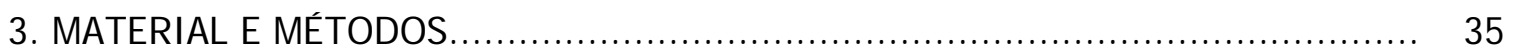

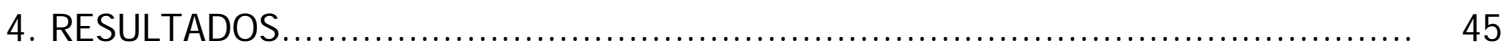

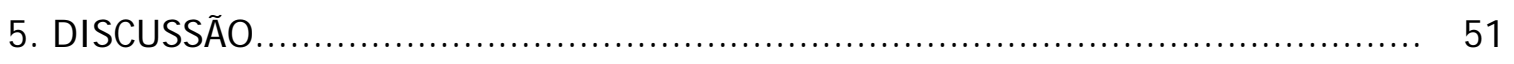

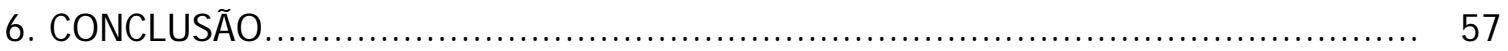

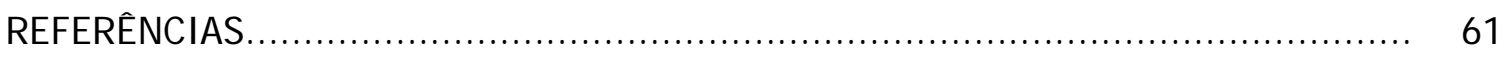

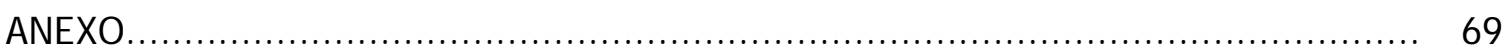

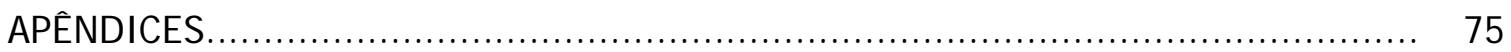





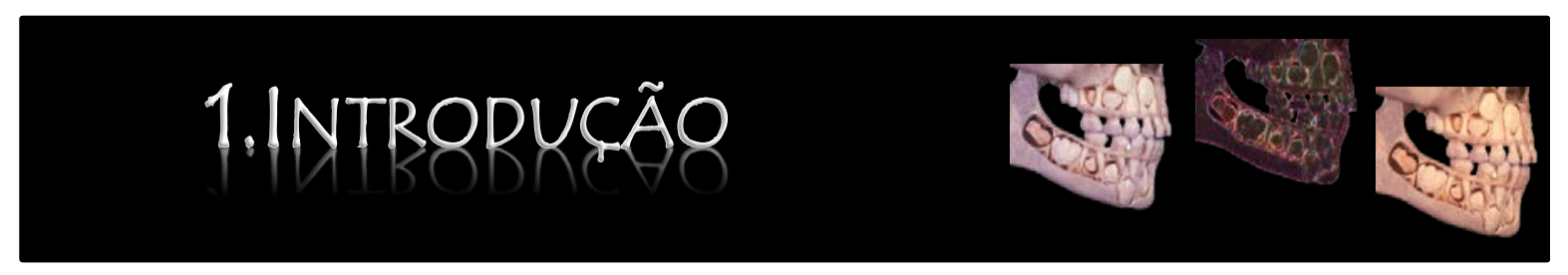





\section{I NTRODUÇÃO}

O processo fisiológico de erupção dentária pode ser definido como o movimento migratório realizado por um dente em formação,do seu local de desenvolvimento, dentro dos processos alveolares, para sua posição funcional na cavidade bucal, iniciando-se nos primórdios da odontogênese e continuando por toda a vida do órgão dentário. Portanto, envolve mais do que a emergência através do tecido gengival (Assed, 2005; Neves, 2003; Silva, 2018).

O processo de erupção dentária é diferente de qualquer outro fenômeno do crescimento humano e a regularidade com que cada dente irrompe na cavidade bucal leva-nos a considerar a cronologia de erupção, ou seja, o momento que os dentes irrompem na cavidade bucal, como um marco do desenvolvimento humano (Cordeiro, 2000). Assim, esforços têm sido empreendidos no sentido de ampliar os conhecimentos sobre o assunto, não somente sobre a cronologia e sequência de erupção ou épocas de mineralização, mas para favorecer a utilização da idade

dentária como auxiliar no diagnóstico dos distúrbios de crescimento e desenvolvimento físico (Cançado, 2003).

A cronologia de erupção, tanto dos dentes decíduos como dos permanentes, pode apresentar variações de acordo com a população e com a área geográfica, podendo ainda ser alterada por fatores gerais ou locais, que atrasam ou aceleram a erupção (Candeiro et al., 2009). Especificamente com relação à erupção de dentes permanentes com antecessores decíduos deve-se atentar para o processo de rizólise fisiológica dos dentes decíduos, o qual auxilia a orientar a erupção do dente sucessor permanente, proporcionando seu correto posicionamento no arco dentário. Todavia, esse fenômeno pode sofrer alterações e acarretar falhas na cronologia de erupção dentária (Vantine et al., 2007). Também, já foi demonstrado em estudos prévios que indivíduos do sexo feminino apresentam aceleração da cronologia de erupção dos dentes permanentes, quando comparados com indivíduos do sexo masculino (Zollner, 1991; Oziegbe et al., 2014).

A cronologia de erupção dentária é considerada fora dos padrões de normalidade quando se desvia dos períodos estabelecidos pelos estudos populacionais. Como salientado anteriormente, as alterações na erupção dentária 
podem estar relacionadas com diversos fatores de ordem local, como tumores e odontomas (Hansen e Kjaer, 2004; Costa et al., 2008), e fatores de ordem geral, como problemas endócrinos e síndrômicos, desnutrição e obesidade (Almonaitiene et al., 2010; Guedes-Pinto, 2010; Sánchez-Perez et al., 2010; Must et al., 2012; Sheetal, 2013; Fatemifar et al., 2014) e fatores genéticos e moleculares (Bath-Balogh et al., 2006; Raberin et al., 2015).

Especificamente com relação ao estado nutricional (desnutrição, sobrepeso e obesidade) e cronologia de erupção estudos prévios em diferentes populações demonstraram que crianças com sobrepeso ou obesas têm mais dentes permanentes irrompidos, quando comparadas com seus controles, sugerindo que os dentes permanentes das crianças com sobrepeso e obesas irrompem mais precocemente (Hilgers et al., 2006; Psoter et al., 2008; Sánchez-Pérez et al., 2010; Costacurta et al., 2012; Must et al., 2012; Heinrich-Weltzien et al., 2013; Mack et al., 2013; Hedayati e Khalafinejad, 2014; Arid et al., 2017).

O peso maior que o considerado normal para uma determinada altura é descrito como sobrepeso ou obesidade. O sobrepeso e a obesidade na infância são um dos mais sérios desafios de saúde pública do século 21 e vem aumentando nos últimos anos. Segundo a Organização Mundial da Saúde (OMS), mais de 42 milhões de crianças são consideradas com sobrepeso ou obesas, sendo sabido que a obesidade está associada a diversos problemas de saúde, incluindo cardiopatias, diabetes, aumento da pressão arterial, problemas articulares e até mesmo câncer (Papáleo Netto, 2005) e antecipação da puberdade (Shiyan et al., 2016). Crianças com sobrepeso são, ainda, mais altas que crianças sem excesso de peso na mesma idade (Kjaer, 2014).

Além disso, a influência dos fatores genéticos no processo de erupção dentária é indiscutível, pois pela própria determinação dos padrões hereditários, cada indivíduo é um modelo original e específico denominado genótipo, o qual pode sofrer influências ambientais, constituindo o fenótipo. Os efeitos dos fatores genéticos interagem de tal forma com uma variedade de fatores ambientais que tentar separálos é um dos mais antigos, difíceis e controvertidos temas da genética humana (Cançado, 2003). 
Diversos mecanismos moleculares podem estar envolvidos no processo de erupção dentária. A erupção dos dentes depende da presença de osteoclastos para criar uma via de erupção através do osso alveolar (Hua et al., 2007). Os osteoclastos são as principais células reabsortivas do osso, degradando os seus constituintes orgânicos e inorgânicos (Baron et al., 1985; Blair et al., 1986). A solubilização da matriz mineralizada é devido à secreção de ácido nesta região (Silver et al., 1988), enquanto que a degradação da matriz orgânica (principalmente colágeno tipo I) deve-se principalmente à atividades de enzimas proteolíticas que são consideradas como pertencendo a duas classes principais: as cisteínas proteinases (CPs) e as MMPs (Everts et al., 1992). Essa degradação é realizada pelas MMPs e seus inibidores teciduais (TIMPS), e cisteínas proteinases, como a catepsina K (Linsuwanont et al., 2002), que atuam não apenas na solubilização da estrutura dental, como também na regulação do início dos processos de reabsorção fisiológicos e patológicos (Delaissé et al., 2000).

As MMPs constituem-se de um grupo de enzimas (endopeptidases) responsáveis pela degradação dos componentes da matriz extracelular (MEC) e das membranas basais, que desempenham importante função na fisiologia e patologia dos tecidos. A descoberta das MMPs provavelmente ocorreu no ano de 1962, quando Gross e Lapièrre encontraram uma enzima ativa na cultura de fragmentos da pele de ratos, a qual degradou a tripla hélice do colágeno tipo I maduro.

A família das MMPs inclui cerca de 25 proteínas (sendo 23 codificadas no genoma humano), as quais podem ser divididas em: colagenases (MMP-1, 8 e 13), gelatinases (MMP-2 e 9), estromelisinas (MMP3, 7 e 10), matrilisinas (MMP-7 e 26), MMPs tipo membrana (MMP-14, 15, 16, 17 e 24) e outras MMPs 3 , que são classificadas pela especificidade ao substrato e, principalmente, de acordo a sua estrutura. Gelatinase B (MMP-9) e gelatinase A (MMP2) são dois membros intimamente relacionados da família MMP que degradam colágeno desnaturado ou gelatinas (Visse e Nagasse, 2003).

São ubíquas no organismo humano, sendo encontradas na pele, gengiva, ossos, cartilagens, córnea ocular, tendões e ligamentos (Kessenbrock et al.,2010). Inúmeros trabalhos vêm se desenvolvendo a fim de elucidar e aprimorar o 
conhecimento sobre as MMPs (Woessner e Nagase, 2000; Sasano et al., 2002; Tsubota et al., 2002; Maruya et al., 2003; Navarro et al., 2006; Sorsa et al., 2006; Room et al., 2009; Maciejczyk et al., 2016; Barreiros et al., 2018).

A penetração das cúspides dentárias no tecido conjuntivo, a qual caracteriza a fase de penetração da mucosa, é marcada por intensa remodelação e destruição da lâmina própria por meio da ação das MMPs. Com isso, ocorre o avanço do elemento dentário em direção à cavidade bucal, na fase avançada do estágio de penetração da mucosa (Cerri, 2010). Assim, não só a especificidade de substrato, como também o padrão de expressão das MMPs varia, sendo a MMP-13 a colagenase com padrão de substrato mais amplo e com expressão mais estritamente regulada. As MMPs-1, -8 e -13 agem degradando os componentes da matriz extracelular (Parks et al., 2004; Sorsa et al., 2006; Hannas et al., 2007; Maciejczyk et al., 2016). No entanto apenas as MMPs-8 e -13 foram identificados em roedores (J effrey, 1998; Woessner e Nagase, 2000).

Os polimorfismos genéticos de nucleotídeo único são polimorfismos de DNA onde somente uma base é alterada, coexistindo alelos múltiplos em determinados locus, frequente em no mínimo $1 \%$ da população. Os polimorfimos genéticos, dispersos por todo o genoma, ocorrem em regiões codificadoras denominadas não sinônimas, podendo ocorrer uma substituição de um aminoácido na sequência proteica que pode levar a modificações estruturais e funcionais na proteína e um potencial biológico. Alguns polimorfismos genéticos classificados como sinônimos podem modificar a estrutura e estabilidade do RNA mensageiro e afetar a quantidade de proteína produzida. Outro tipo de polimorfismo, também importante, é aquele localizado em regiões promotoras, pois são capazes de alterar a expressão do gene (Chasman e Adams, 2001).

Embora vários estudos sobre MMPs têm sido realizados com o intuito de esclarecer os processos fisiológicos que ocorrem durante a reparação celular, além de estudar as alterações ocorridas durante os processos patológicos (Gan,2001). No entanto, até o presente momento, não existe na literatura nenhum estudo sobre a associação de polimorfismos nos genes que codificam as MMPs com cronologia de erupção dentária. 


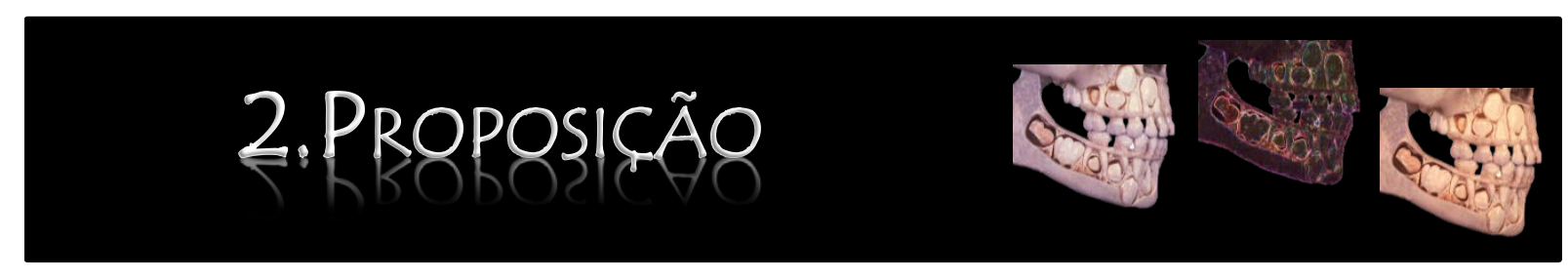





\section{Proposição}

Os objetivos do presente estudo foram avaliar, em crianças do município de Manaus - AM:

- Se o sobrepeso e a obesidade estão associados com a cronologia de erupção de dentes permanentes.

- Se os polimorfismos genéticos nos genes que codificam as MMPs -8 e -13 estão associados com a cronologia de erupção dos dentes permanentes. 

3. MATERIAL E MÉTOPOS 



\section{Materi al e Métodos}

O presente estudo foi submetido à apreciação pelo Comitê de Ética em Pesquisa da Universidade do Estado do Amazonas - UEA (CAAE: 39129614.3.0000.5016; Parecer: 923.569 - Anexo A), tendo sido aprovado.

\subsection{Amostra}

A amostra, por conveniência, foi constituída de 216 participantes, com idade entre 9 e 12 anos, alunos das Escola Municipal Thomas Meirelles, Escola Municipal Paula Frassinetti, Centro de Educação de Tempo Integral (CETIS) do bairro Educandos e Compensa, do município de Manaus, que é a capital do estado do Amazonas e localiza-se na região Norte do Brasil, situando-se na floresta amazônica e tendo população total de 2.094.391 habitantes. A ancestralidade dos habitantes de Manaus é composta principalmente por europeus e nativos americanos, e o restante de descendentes de africanos (WHO, 2006).

\subsection{Aspectos Éticos}

Os participantes da pesquisa e/ou responsáveis foram informados sobre o projeto de pesquisa e foram incluídos neste estudo após ler e assinar a Carta de Informação ao Participante da Pesquisa, o Termo de Consentimento Livre e Esclarecido (TCLE) e Termo de Assentimento (Apêndices A, B e C), nos quais os objetivos, benefícios e riscos inerentes ao estudo estavam descritos. Após a autorização de participação, foi aplicado o questionário (Apêndice $D$ ) e realizado o exame clínico intrabucal.

\subsection{Critérios de exclusão}

Foram excluídos da amostra indivíduos que apresentassem:

- Alterações sistêmicas;

- Síndromes genéticas;

- Dentes com histórico de trauma;

- Dentes com perda precoce por cárie dentária ou traumatismo dentofacial;

- Ausência visível de espaço no arco para erupção dentária; 
- Uso de aparelho ortodôntico fixo ou removível;

- Consanguinidade;

- Baixo peso ou desnutrição.

\subsection{Delineamento do estudo}

\subsubsection{Anamnese}

Durante a anamnese foram coletados dados relacionados as crianças tais como dados familiares, sexo, idade e história médica (Apêndice D).

\subsubsection{Determinação do estado nutricional}

Das 216 crianças selecionadas para a pesquisa, 24 não compareceram nas datas agendadas para obtenção do peso e da altura, sendo assim, foram excluídas desta fase do estudo.

A altura de cada criança foi determinada em centímetros $(\mathrm{cm})$, empregando fita antropométrica (T87-2 WISO, São Paulo - SP, Brasil). O peso, em quilogramas $(\mathrm{Kg})$, foi avaliado utilizando-se um aparelho de pesagem (Balança Accumed Balmaz Analógica, Rio de Janeiro - RJ, Brasil) (Silva et al., 2016). O Índice de Massa Corporal (IMC) score-z foi calculado pelo Pediatric Z-Score Calculator do Hospital de Crianças da Filadélfia (http://zscore.research.chop.edu/index.php), usando as variáveis individuais altura, peso, idade e sexo. O status nutricional foi classificado conforme parâmetros definidos pela Organização Mundial da Saúde (WHO, 2006), conforme pode ser observado na tabela 1.

\begin{tabular}{lcc}
\multicolumn{3}{c}{ Tabela 1 - Classificação do status nutricional, com base no IMC escore-z } \\
\hline \multicolumn{1}{c}{ Status Nutricional } & I MC score-z & Percentil \\
\hline Baixo peso & $<-2$ & $<3$ \\
Eutrófico & $\geq-2 \mathrm{e} \leq+1$ & $\geq 3 \mathrm{e} \leq 85$ \\
Sobrepeso & $>+1 \mathrm{e} \leq+2$ & $>85 \mathrm{e} \leq 97$ \\
Obeso & +2 & $>97$ \\
\hline IMC: Índice de Massa Corporal. & &
\end{tabular}




\subsubsection{Exame Clínico Intrabucal}

\subsubsection{Avaliação da cronologia de erupção}

Previamente à coleta de dados, uma equipe composta por dois cirurgiõesdentistas (examinadores) e um anotador participaram do processo de calibração, no qual um examinador experiente em levantamentos epidemiológicos (Gold-Standard) procedeu às etapas de treinamento teórico e prático. Os examinadores foram instruídos quanto aos critérios de diagnóstico e codificação. O exame clínico foi realizado sob luz artificial, utilizando-se espátula de madeira (Golgran ${ }^{\circledR}$, São Paulo SP, Brasil).

O número de dentes permanentes irrompidos na cavidade bucal de cada paciente foi avaliado, assim como a presença de fatores que poderiam alterar a cronologia de erupção.

A avaliação da cronologia de erupção foi baseada na tabela proposta por Marques et al. (1978), para a população brasileira, que indica a idade padrão de erupção de cada dente, de acordo com o sexo. Desta forma, a criança foi considerada com atraso de erupção quando pelo menos um dente permanente não estivesse presente na cavidade bucal no período sugerido pela tabela de cronologia de erupção (Tabela 2).

Tabela 2 - Cronologia de erupção proposta por Marques et al. (1978), como padrão para crianças brasileiras

\begin{tabular}{|c|c|c|c|}
\hline Arco & Dente & Gênero masculino & Gênero feminino \\
\hline \multirow{7}{*}{ Superior } & 1 & 7 а 7,5 & 6,5 a 7 \\
\hline & 2 & 8 a 8,5 & 7,5 a 8,5 \\
\hline & 3 & 11,5 a 12 & 10,5 a 11 \\
\hline & 4 & 9,5 a 10 & 9 a 9,5 \\
\hline & 5 & 10,5 a 11 & 10 a 10,5 \\
\hline & 6 & 6 a 6,5 & 6 a 6,5 \\
\hline & 7 & 12 a 12,5 & 12 a 12,5 \\
\hline \multirow{7}{*}{ Inferior } & 1 & 6 a a 6,5 & 5,5 a 6 \\
\hline & 2 & 7 a 7,5 & 7,5 a 8,5 \\
\hline & 3 & 10 a 10,5 & 9 a 9,5 \\
\hline & 4 & 9,5 a 10,5 & 9,5 a 10,5 \\
\hline & 5 & 11 a 12 & 10,5 a 11 \\
\hline & 6 & 6 a 6,5 & 5,5 a 6,5 \\
\hline & 7 & 12 a 12,5 & 11 a 11,5 \\
\hline
\end{tabular}




\subsubsection{Coleta do material biológico}

Amostras de saliva foram coletadas como fonte de DNA genômico, com base em um protocolo previamente publicado (Kuchler et al., 2012) e posteriormente armazenadas, processadas e analisadas no Laboratório de Biologia Molecular do Departamento de Clínica Infantil da Faculdade de Odontologia de Ribeirão Preto Universidade de São Paulo. Cada criança realizou um bochecho com $5 \mathrm{~mL}$ de solução salina, durante 1 minuto. Todo o volume do bochecho foi acondicionado em tubos (Cralplast, São Paulo - SP, Brasil) de $15 \mathrm{~mL}$ e mantido a $-20^{\circ} \mathrm{C}$. Cada tubo contendo a suspensão salivar foi centrifugado a $550 \mathrm{~g}$ durante 10 minutos para sedimentação do pellet de células. O sobrenadante foi descartado em hipoclorito de sódio a 2,5\% e o pellet ressuspendido em $1 \mathrm{~mL}$ de tampão de extração (TE) (Tris-HCl $10 \mathrm{mM}, \mathrm{pH}$ 7,8; EDTA $5 \mathrm{mM}$; 0,5\%). Posteriormente, o material biológico foi transferido para um tubo de $1,5 \mathrm{~mL}$ e SDS congelado a $-20^{\circ} \mathrm{C}$, até o momento da extração do DNA.

\subsubsection{Extração de DNA}

As amostras foram descongeladas e incubadas com 100 $\mathrm{ng} / \mathrm{ml}$ de Proteinase $\mathrm{K}$ em banho-maria a $56^{\circ} \mathrm{C}$ overnight e submetidas a processos de precipitação, utilizando-se $400 \mu \mathrm{L}$ de solução de acetato de amônio a 10M. A seguir, todos os tubos foram agitados manualmente por 5 minutos e centrifugados por 15 minutos (12000rpm). O sobrenadante foi dividido em dois tubos de 700 $\mu \mathrm{L}$ cada. O mesmo volume de álcool isopropílico gelado ( $700 \mu \mathrm{L})$ foi adicionado em cada espécime e agitado manualmente de maneira vigorosa. Foi observada a formação de "nuvem de DNA" em cada espécime de todas as alíquotas que posteriormente foram centrifugadas por 20 minutos a 12000rpm. Então, o sobrenadante foi descartado com cuidado para não deslocar o pellet de DNA, e $1 \mathrm{~mL}$ de etanol $70 \%$ gelado foi adicionado e centrifugado por 15 minutos a 12000rpm. Posteriormente, o sobrenadante foi descartado e o tubo foi aberto e emborcado em papel para secar por pelo menos 30 minutos e evaporar o excesso de etanol 70\%. O pellet de DNA foi ressuspendido em $50 \mu \mathrm{L}$ de TE e congelado a $-20^{\circ} \mathrm{C}$. 


\subsubsection{Avaliação da quantidade e da pureza do DNA}

A concentração e a pureza do DNA foram determinados por densidade óptica em espectrofotômetro (NanoDrop ${ }^{\circledR}$ 2000c- Thermo Fischer Scientific, Walthan, Massachusetts, EUA) utilizando-se $2 \mu \mathrm{L}$ do material extraído. A concentração de DNA foi avaliada em um comprimento de onda de $260 \mathrm{~nm}$. A razão entre os valores obtidos nos comprimentos de onda $260 \mathrm{~nm}$ e $280 \mathrm{~nm}$ foi usada para estimar a pureza do DNA genômico. Somente as amostras de DNA com razão 260/280 acima de 1,8 foram incluídas neste estudo.

\subsubsection{Seleção dos Polimorfismos e Genotipagem}

Foram selecionados polimorfismos genéticos em MMP8 e MMP13, que compreendem a subfamília colagenase em humanos. A MMP-13 é a única colagenase intersticial sugerida por degradar colágenos em tecidos conjuntivos em ratos (Jeffrey, 1998). Já a MMP-8 é predominantemente expressa por neutrófilos (Tschesche e Pieper, 1998; Woessner e Nagase, 2000), no entanto estudos indicam que pode ser expressa em outros tipos de células, como os condrócitos articulares (Cole et al., 1996), fibroblastos sinoviais, células endoteliais (Hanemaaijer et al., 1997), odontoblastos, células da polpa dentária (Palosaari et al., 2000), osteoblastos e osteócitos (Sasano et al., 2002).

Esses polimorfismos nos genes selecionados codificam MMPs, sendo assim potencialmente candidatos ao estudo da erupção dentária. Assim, optou-se por polimorfismos de um único nucleotídeo, por serem capazes de influenciar a expressão gênica, aumentando ou diminuindo a quantidade final da proteína codificada por aquele gene (Shastry, 2003). Optou-se também por polimorfismos previamente associados a patologias e alterações do desenvolvimento dentário na população brasileira (Tabela 3). 
Tabela 3 - Características genéticas dos polimorfismos selecionados para o estudo

\begin{tabular}{cccc}
\hline Gene & $\begin{array}{c}\text { Sequência de } \\
\text { Referência }\end{array}$ & Tipo de alteração & Global MAF* \\
\hline MMP8 & rs17099443 & Variante intronica & 0,34 \\
MMP8 & rs3765620 & T [Thr] > I [lle] & 0,34 \\
MMP13 & rs478927 & Variante intronica & 0,36 \\
MMP13 & rs2252070 & upstream variant & 0,36 \\
\hline
\end{tabular}

Fonte de informação: dbSNP de: https://www.ncbi.nlh.nih.gov/snp/

* MAF: Minor Allele Frequency (Freqüência do Alelo Menor)

O método utilizado para as reações foi o de TaqMan (Ranade, et al., 2001) com sondas específicas para a distinção alélica (sondas TaqMan). As sondas TaqMan baseiam-se na identificação da base com uso de sondas marcadas com fluoróforos. Além do primer, um par de sondas se anela sobre uma pequena sequência de nucleotídeos que contém o polimorfismo, sendo cada uma específica para um dos alelos, o polimórfico e o tipo selvagem. As sondas apresentam um fluoróforo que absorve a energia luminosa emitida pelo termociclador (Applied Biosystem 7500 Thermo Fisher Scientific, Walthan, Massachusetts, EUA) que dissipa na forma de luz e calor, em comprimento de onda diferente do original. Essa fluorescência é então detectada pelo aparelho.

A reação de PCR em tempo real foi realizada contendo um volume final de 3 $\mu \mathrm{L}$ (4 ng de DNA/reação, 1,5 $\mu \mathrm{L}$ de TaqMan PCR master mix, 0,075 de SNP assaybyDesign (Applied Biosystems-Foster City, CA) e água deionizada q.s.p.). Para amplificação 40 ciclos foram realizados de $95^{\circ} \mathrm{C}$ por 10 minutos, $92{ }^{\circ} \mathrm{C}$ por 15 segundos e $60^{\circ} \mathrm{C}$ por 1 minuto. Então a genotipagem dos polimorfismos rs17099443 e rs3765620 em MMP8 e dos polimorfismos rs478927 e rs2252070 em MMP13 foi realizada pela análise do produto final de PCR amplificado com Taqman.

\subsection{Análise dos dados}

Os dados foram analisados no programa Epi Info 7 (Centers for Disease Control and Prevention, Atlanta, USA). O grupo "sobrepeso/obeso" foi comparado com o grupo "peso normal" e comparado na proporção de 1:2. O teste de ShapiroWilk foi utilizado para verificar a normalidade dos dados. O teste t baseado na idade foi utilizado para comparação das médias entre os grupos. Uma análise de regressão linear usando idade e sexo como co-variantes foi utilizada. 
Para análise dos dados referentes à erupção dental, os pacientes foram divididos em 2 grupos: indivíduos "sem atraso de erupção" e indivíduos "com atraso de erupção", de acordo com a idade e gênero de cada paciente, especificada em cada ficha clínica. Os dados foram tabulados no Excel 2013 (Microsoft Office Professional Plus, versão 2013), analisados programa estatístico Epi Info 7 (Centers for Disease Control and Prevention, Atlanta, USA) e no programa GraphPad Prism (Inc. San Diego, California, USA) . Para avaliação da associação entre as variáveis categóricas, o teste de associação qui-quadrado ou teste exato de Fisher foi utilizado. Para a comparação das médias, foi utilizado o teste $t$.

Os testes do qui-quadrado e/ou exato de Fisher foram utilizados para comparar crianças com e sem atraso na cronologia de erupção, com relação à genotipagem. O teste Anova com pós-teste de Tukey foi utilizado para comparar o número de dentes com atraso da cronologia de erupção, de acordo com o genótipo.

O nível de significância adotado para todas as análises foi de 5\%. 



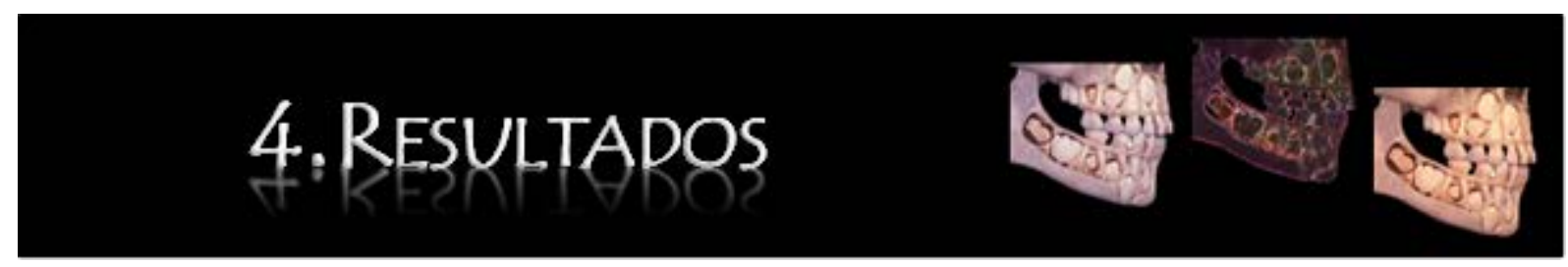





\section{Resultados}

Das 216 crianças incluídas, 108 (50\%) eram meninos e 108 (50\%) eram meninas. Oitenta e sete $(40,3 \%)$ crianças apresentavam dentição mista e 129 $(59,7 \%)$ dentição permanente. Um total de 126 crianças foram classificadas como 'com atraso na cronologia de erupção' e 90 como 'sem atraso na cronologia de erupção'. As características da amostra estão apresentadas na Tabela 4.

Tabela 4 - Características da população estudada
\begin{tabular}{ll}
\hline Sexo \\
\hline Masculino (\%) & $108(50 \%)$ \\
Feminino (\%) & $108(50 \%)$ \\
\hline Erupção dentária & \\
\hline Com atraso (\%) & $126(58,5 \%)$ \\
Sem atraso (\%) & $90(41,5 \%)$ \\
\hline Dentição & \\
\hline Mista & $87(40,3 \%)$ \\
Permanente & $129(59,7 \%)$ \\
\hline
\end{tabular}

Um total de 127 crianças apresentaram peso normal, enquanto 65 crianças apresentaram sobrepeso/obesidade (49 estavam com sobrepeso e 16 eram obesos). A distribuição das características de acordo com os grupos está apresentada na Tabela 5. Sobrepeso/obesidade estavam associados ao sexo, no qual os meninos tiveram maior chance de apresentar aumento de peso (OR $=1,84$; IC 95\% 1,06$3,37 ; p=0,04)$.

Tabela 5 - Distribuição das características da amostra entre os grupos

\begin{tabular}{llll}
\hline Características & Peso Normal & Sobrepeso/ obeso & p-valor \\
\hline Sexo $n(\%)$ & & & $0,04^{*}$ \\
\hline Masculino & $55(43,31)$ & $38(40,9)$ & \\
Feminino & $72(56,69)$ & $27(27,3)$ & 0,21 \\
Média idade (SD) & $10,40(8,18)$ & $10.22(0,94)$ &
\end{tabular}

A média do número de dentes permanentes irrompidos foi maior no grupo de crianças com sobrepeso/obesidade. Observou-se associação quando a análise foi realizada em ambos os sexos e quando analisou-se individualmente cada sexo. A 
distribuição da média de acordo com o estado nutricional, e estratificada segundo o sexo, está apresentada na Tabela 6.

Tabela 6 - Média do número de dentes permanentes irrompidos, de acordo com os grupos, e estratificado de acordo com o sexo

\begin{tabular}{|c|c|c|c|}
\hline \multirow{3}{*}{$\begin{array}{c}\text { Grupos } \\
\text { Estado nutricional }\end{array}$} & \multicolumn{2}{|c|}{ Número de dentes erupcionados } & \multirow[b]{3}{*}{ p-valo } \\
\hline & Mínimo-máximo & Média (SD) & \\
\hline & \multicolumn{2}{|c|}{ Ambos os sexos } & \\
\hline Peso normal & $10-28$ & $20,36(5,25)$ & \multirow{2}{*}{$<0,001^{*}$} \\
\hline \multirow{2}{*}{ Sobrepeso/obeso } & $12-28$ & $22,63(4.89)$ & \\
\hline & \multicolumn{2}{|c|}{ Masculino } & \\
\hline Peso normal & $10-28$ & $18,86(4.78)$ & \multirow{2}{*}{$<0,001^{*}$} \\
\hline \multirow[t]{2}{*}{ Sobrepeso/obeso } & $12-28$ & $21,48(4.98)$ & \\
\hline & \multicolumn{2}{|c|}{ Feminino } & \\
\hline Peso normal & $10-28$ & $21,47(5,31)$ & \multirow{2}{*}{$<0,001 *$} \\
\hline Sobrepeso/obeso & $14-28$ & $24,21(4,30)$ & \\
\hline
\end{tabular}

SD desvio padrão; * diferença estatística $(p<0,05)$

A Tabela 7 mostra os resultados da análise de regressão linear dos fatores envolvidos no número de dentes permanentes irrompidos. O estado nutricional, 0 sexo e a idade foram fortemente associados ao número de dentes permanentes irrompidos $(p<0,05)$.

Tabela 7 - Regressão linear para avaliar os fatores que influenciaram o número de dentes permanentes irrompidos

\begin{tabular}{lcc}
\hline \multicolumn{1}{c}{$\mathbf{R}^{\mathbf{2}}$} & $\mathbf{0 , 4 3}$ \\
\hline Variáveis independentes & $\mathbf{S E}$ & $\mathbf{p}$-valor \\
Estado nutricional & 0,62 & $0,001^{*}$ \\
Sexo & 0,59 & $0,025^{*}$ \\
I dade & 0,32 & $<0,001^{*}$ \\
\hline SE erro padrão. *diferença estatística $(\mathrm{p}<0,05)$ & &
\end{tabular}

A Tabela 8 apresenta o genótipo e a distribuição alélica entre os grupos com e sem atraso na erupção, onde em MMP13 não foi encontrada nenhuma diferença estatística entre os grupos. No entanto no genótipo GG e o alelo $\mathrm{G}$ do polimorfismo genético rs17099443 em MMP8 foram encontrados mais frequentemente nas crianças com atraso de erupção ( $p=0,050$ e $p=0,013$, respectivamente). Crianças com o genótipo GG (modelo recessivo) nesse polimorfismo apresentavam mais atraso de erupção que as crianças com os genótipos CC e CG ( $p=0,01)$. 
Tabela 8 - Genótipos e alelos distribuídos de acordo com os grupos (com atraso de erupção e sem atraso de erupção)

\begin{tabular}{|c|c|c|c|c|c|c|c|c|c|}
\hline \multirow{3}{*}{$\begin{array}{c}\text { Gene/ } \\
\text { Polimorfismo } \\
\text { MMP8 } \\
\end{array}$} & Grupos & \multicolumn{3}{|c|}{ Genótipo n(\%) } & \multirow[t]{2}{*}{ p-valor } & \multicolumn{2}{|c|}{ Alelo $n(\%)$} & \multirow[t]{2}{*}{ p-valor } & \multirow{2}{*}{$\begin{array}{c}\text { OR } \\
(95 \% \mathrm{Cl})\end{array}$} \\
\hline & & CC & CG & GG & & C & G & & \\
\hline & Com atraso na erupção & $23(18,70 \%)$ & $36(29,27 \%)$ & $64(52,03 \%)$ & \multirow[t]{2}{*}{0,050} & $82(33,33 \%)$ & $164(66,67 \%)$ & \multirow[t]{2}{*}{$0,013^{*}$} & \multirow[t]{2}{*}{$0,60(0,40-0,90)$} \\
\hline & Sem atraso na erupção & $22(25 \%)$ & $35(39,77 \%)$ & $31(35,23 \%)$ & & $80(45,20 \%)$ & $97(54,80 \%)$ & & \\
\hline \multirow{3}{*}{$\begin{array}{c}\text { MMP8 } \\
\text { rs3765620 }\end{array}$} & & AA & AG & GG & \multirow{3}{*}{0,821} & $\mathbf{A}$ & $\mathbf{G}$ & \multirow{3}{*}{0,652} & \multirow{3}{*}{$0,91(0,60-1,36)$} \\
\hline & Com atraso na erupção & $36(31,30 \%)$ & $45(39,13 \%)$ & $34(29,57 \%)$ & & $117(50,87 \%)$ & $113(49,13 \%)$ & & \\
\hline & Sem atraso na erupção & $27(34,61 \%)$ & $29(37,18 \%)$ & $22(28,21 \%)$ & & $83(53,20 \%)$ & $73(46,80 \%)$ & & \\
\hline \multirow{3}{*}{$\begin{array}{l}\text { MMP13 } \\
\text { rs478927 }\end{array}$} & & CC & CT & $T T$ & \multirow{3}{*}{0,133} & C & $\mathbf{T}$ & \multirow{3}{*}{0,701} & \multirow{3}{*}{$1,08(0,7-1,64)$} \\
\hline & Com atraso na erupção & $13(11,02 \%)$ & $46(38,98 \%)$ & $59(50 \%)$ & & $112(48,27 \%)$ & $120(51,73 \%)$ & & \\
\hline & Sem atraso na erupção & $8(9,76 \%)$ & $29(35,36 \%)$ & $45(54,88 \%)$ & & $68(46,26 \%)$ & $79(53,74 \%)$ & & \\
\hline \multirow{3}{*}{$\begin{array}{c}\text { MMP13 } \\
\text { rs2252070 }\end{array}$} & & CC & CT & $T T$ & \multirow{3}{*}{0,780} & $\mathbf{C}$ & $\mathbf{T}$ & \multirow{3}{*}{0,524} & \multirow{3}{*}{$1,15(0,74-1,79)$} \\
\hline & Com atraso na erupção & $33(28,45 \%)$ & $46(39,65 \%)$ & $37(31,90 \%)$ & & $72(30,38 \%)$ & $165(69,62 \%)$ & & \\
\hline & Sem atraso na erupção & $23(28,75 \%)$ & $22(27,5 \%)$ & $35(43,75 \%)$ & & $45(27,99 \%)$ & 119 (72,01\%) & & \\
\hline
\end{tabular}

O teste qui-quadrado foi usado.

* diferença estatística. OR= proporção da probabilidade; $\mathrm{Cl}=$ Intervalo de confiança. 
A Tabela 9 apresenta a média e o desvio padrão apenas dos dentes com atraso de erupção, de acordo com o genótipo. O polimorfismo rs17099443 em MMP8 estava associado com o aumento no número de dentes permanentes com atraso de erupção, onde o genótipo GG demonstrou ter uma média estatisticamente maior do que os genótipos CC e CG $(p=0,01)$.

Tabela 9 - Média e desvio padrão do número de dentes com atraso de erupção de acordo com o genótipo

\begin{tabular}{|c|c|c|c|c|}
\hline Gene/ poliporfismo & Méd & $\begin{array}{l}\text { ótipo dos de } \\
\text { de erupção }\end{array}$ & & p valor \\
\hline $\begin{array}{c}\text { MMP8 } \\
\text { (rs17099443) }\end{array}$ & $\frac{\text { CC }}{2,33(3,23)}$ & $\begin{array}{c}\text { CG } \\
2,28(2,93)\end{array}$ & $\begin{array}{c}\mathbf{G G} \\
3,61(3,62)\end{array}$ & $0,01^{*}$ \\
\hline $\begin{array}{c}\text { MMP8 } \\
\text { (rs3765620) }\end{array}$ & $\frac{\mathbf{A A}}{2,42(3,01)}$ & $\begin{array}{c}\text { AG } \\
2,68(3,15)\end{array}$ & $\frac{\mathbf{G G}}{3,53(3,73)}$ & 0,16 \\
\hline $\begin{array}{c}\text { MMP13 } \\
\text { (rs478927) }\end{array}$ & $\begin{array}{c}\text { CC } \\
2,57(3,07)\end{array}$ & $\begin{array}{c}\text { CT } \\
3,23(3,36)\end{array}$ & $\frac{\mathbf{T}}{2,83(3,48)}$ & 0,53 \\
\hline $\begin{array}{c}\text { MMP13 } \\
\text { (rs2252070) }\end{array}$ & $\begin{array}{c}\frac{\text { CC }}{2,85(3,03)} \\
\end{array}$ & $\begin{array}{c}\mathbf{C T} \\
3,18(3,62)\end{array}$ & $\frac{\mathbf{T}}{2,84(3,33)}$ & 0,74 \\
\hline
\end{tabular}

Notas: Kruskal-Wallis com Dunns foi usado.

*Indica diferença estatística $(p<0,05)$

A diferença estatístisca foi entre os genótipos CG e GG. 


\section{RIsCUSSSĀO}





\section{DisCUSSÃo}

O sobrepeso e a obesidade infantil são um grave problema de saúde pública. Esse problema é global e tem acometido muitos países de baixa e média renda, principalmente em áreas urbanas (WHO, 2006). Este estudo foi realizado na cidade de Manaus, capital do estado do Amazonas - Brasil. Manaus é uma área urbana e é a maior cidade do norte do Brasil, que representa a sexta maior economia do país (IBGE, 2010).

O impacto negativo do excesso de peso e obesidade na saúde do indivíduo é o fator determinante em várias pesquisas sobre o impacto das condições do estado nutricional na saúde bucal. Sabe-se que o estado nutricional desempenha um papel na saúde e desenvolvimento bucal das crianças (Fonseca, 2017), mas alguns aspectos e a natureza dessa relação permanecem obscuros.

A análise do escore-z do IMC é uma ferramenta útil para avaliar a saúde da criança e pode ser usada para analisar a associação entre o estado nutricional com muitos aspectos, tais como desenvolvimento dentário, esquelético e motor (DuPlessis et al., 2016; Amouian et al., 2017). Neste estudo empregou-se esse método para classificar o estado nutricional das crianças e para avaliar se existe uma associação entre IMC e cronologia de erupção dentária.

Uma população singular de crianças da Amazônia brasileira foi avaliada neste estudo, e os resultados obtidos no presente estudo estão de acordo com estudos prévios realizados em diferentes populações, em que o sobrepeso, e principalmente a obesidade, foram associados a alterações na cronologia de erupção (Hilgers et al., 2006; Sánchez-Pérez et al., 2010; Khan, 2011; Costacurta et al., 2012; Must et al., 2012; Mack et al., 2013; Hedayati e Khalafinejad, 2014). No presente estudo, crianças com sobrepeso/obesidade apresentavam maior número de dentes permanentes irrompidos. Esse achado pode ser explicado pelo fato de crianças com sobrepeso e obesidade apresentarem, mais frequentemente, alterações no metabolismo hormonal e puberdade precoce (Fonseca, 2017), sendo possível que estas condições contribuam para a antecipacão do momento de erupção dentária.

A influência do sexo na cronologia de erupção dentária está bem estabelecida na literatura (Diamanti e Townsend, 2003; Leroy et al., 2003; Moslemi, 
2004; Khan, 2011; Lakshmappa et al., 2011; Oziegbe et al., 2014). Este estudo também permitiu observar que as meninas apresentavam maior número de dentes permanentes irrompidos do que os meninos. Talvez esse achado se deva ao fato das meninas amadurecerem mais cedo que os meninos, incluindo o desenvolvimento e a erupção dentária (Bramen et al., 2011; Eskeli et al., 2016). Por esse motivo, no presente estudo a análise estratificou a amostra de acordo com o sexo, em que crianças com sobrepeso/obesidade de ambos os sexos apresentaram maior número de dentes permanentes irrompidos.

Alguns estudos prévios mostraram que a cronologia de erupção dentária pode variar de acordo com a origem da população (Diamanti e Townsend, 2003; Leroy et al., 2003; Moslemi, 2004; Lakshmappa et al., 2011; Marceua et al., 2011; Oziegbe et al., 2014). Ressalta-se que este é o primeiro estudo a avaliar o impacto do sobrepeso e da obesidade na cronologia de erupção dentária em uma população da região amazônica, que apresenta um fundo genético particular, com uma mistura de descendentes de europeus e nativos sul-americanos e, de fato, nossos resultados permitiram verificar que em crianças amazônicas o estado nutricional também está associado com a cronologia de erupção dentária.

A erupção dentária envolve diversos processos, podendo o alongamento da raiz, remodelação óssea, formação óssea alveolar, ligamento periodontal e folículo dentário estarem envolvidos (Assed, 2005). Esses processos dinâmicos são acompanhados pela extensa degradação e reorganização do colágeno, por moléculas de matriz não-colagenosa, tais como MMPs (Marks e Schroeder, 1996; Maruya et al., 2003). Estudos têm sugerido que as MMPs estão envolvidas na remodelação da matriz extracelular periodontal durante erupção dentária em ratos (Tsubota et al. 2002; Maruya et al., 2003).

Desta forma, no presente estudo decidiu-se por estudar se polimorfismos genéticos em MMPs estão associados com alterações na cronologia de erupção dentária, em crianças.

Com relação à distribuição do genótipo e a distribuição alélica entre os grupos com e sem atraso na cronologia de erupção, os genótipo GG e o alelo $\mathrm{G}$ do polimorfismo genético rs17099443 em MMP8 foram encontrados mais frequentemente nas crianças com atraso de erupção, onde crianças com o genótipo 
GG nesse polimorfismo apresentavam um maior número de dentes permanentes com atraso de erupção do que as crianças com os genótipos CC e CG. Assim o polimorfismo genético rs17099443 em MMP8 poderia ser considerado um possível marcador de atraso na cronologia de erupção de dentes permanentes.

Cabe aqui ressaltar que este estudo apresenta algumas limitações. A maior limitação se deve ao fato do diagnóstico de atraso de erupção dentária ter sido realizado apenas por meio de exame clínico. Apesar do exame radiográfico ser fundamental para determinar se há atraso de erupção, cabe aqui ressaltar que por questões éticas essas crianças não puderam ser submetidas a exames radiográficos, uma vez que nenhum dos elementos dentários foi categorizado com retenção prolongada de dente decíduo. Desta forma, é possível que alguns casos tenham sido diagnosticados como atraso de erupção e tenham outra alteração envolvida impedindo a erupção deste dente. Entretanto, é importante enfatizar que casos como atraso de erupção em decorrência de odontomas, dentes supranumerários e agenesias de pré-molares, são raros (Assed, 2005). Desta forma, a probabilidade que pacientes portadores de odontomas, dentes supranumerários ou agenesias de pré-molares tenham sido incluídos nessa amostra é de apenas 1-3\%.

Embora saiba-se que a influência de fatores genéticos é um item relevante no desenvolvimento das dentições, sendo as mutações genéticas capazes de ocasionar desde alterações na cronologia de erupção dentária até ausências completas de dentições, esse campo de pesquisa precisa ainda ser vastamente explorado na Odontologia. Ressaltamos a importância do presente estudo devido ao ineditismo do tema abordado, entretanto esse mesmo ineditismo dificulta a discussão mais aprofundada de nossos resultados. 



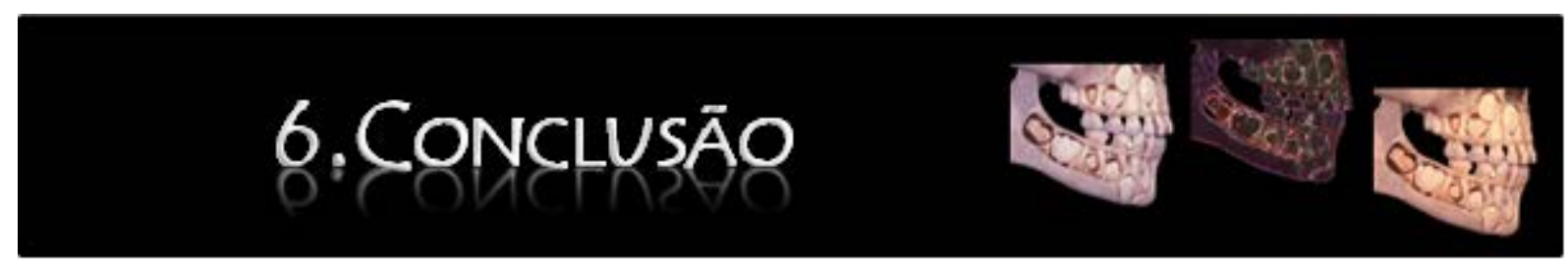





\section{CONCLUSÃo}

Com base na metodologia empregada e nos resultados obtidos, concluiu-se que:

- Crianças manauaras com sobrepeso/obesidade apresentam aceleração na cronologia de erupção dentária, quando comparadas com crianças com peso normal.

- Não houve associação do gene MMP13 com atraso na cronologia de erupção.

- O polimorfismo rs17099443 em MMP8 está associado com atraso na cronologia de erupção dentária, onde o genótipo GG e o alelo G foram encontrados mais frequentemente nas crianças com atraso de erupção. Crianças com o genótipo GG nesse polimorfismo apresentavam um maior número de dentes permanentes com atraso da cronologia de erupção do que as crianças com os genótipos CC e CG. 



\section{BEFERÊNCIAS}





\section{REFERÊNCIAS}

Almonaitiene R, Balciuniene I, Tutkuviene J. Factors influencing permanent teeth eruption: Part one - general factors. Stomatologija Baltic Dent Maxillofac. 2010;12(3):67-72.

Amouian S, Abbasi-Shaye Z, Mohammadian S, Bakhtiari M.; Parsianmehr B. Assessment of the Relationship between Body Mass Index and Gross Motor Development in Children. Iran J Child Neurol. 2017 Summer;11(3): 7-14.

Arid J, Vitiello MC, Silva RAB, Silva LAB, Queiroz AM, Kuchler EC, Nelson-Filho P. Nutricional status is associated with permanent tooth eruption chronology. Brazilian J ournal of Oral Sciences. 2017; 16:1-4.

Assed S. Odontopediatria: bases científicas para a prática clínica. 1a ed. Ribeirão Preto (SP): Artes Médicas; 2005.

Baron R, Neff L, Louvard D, Courtoy PJ. Cell-mediated extracellular acidification and bone resorption: evidence for a low $\mathrm{pH}$ in resorbing lacunae and localization of a 100-kD lysosomal membrane protein at the osteoclast ruffled border. J Cell Biol. 1985 Dec; 101(6):2210-22.

Barreiros D, Nelson-Filho P, Paula- Silva FWG, Oliveira K, Morant HD, et al. MMP2 and MMP9 are Associated with Apical Periodontitis Progression and Might be Modulated by TLR2 and MyD88. Braz Dent J. 2018 J an-Feb;29(1):43-47.

Bath-Balogh MJ, Fehrenbach RDH, editors. Ilustrated Dental Embryology, Histology, and Anatomy. 4th ed. Elsevier Saunders; 2006. P. 352:84-85.

Blair HC, Kahn AJ, Crouch EC, J effrey JJ, Teitelbaum SL. Isolated osteoclasts resorb the organic components of bone. J Cell Biol. 1986 Apr; 102(4):1164-72.

Bramen JE, Hranilovich JA, Dahl RE, Forbes EE, Chen J, Toga AW, Dinov ID, Worthman CM, Sowell ER. Puberty influences medial temporal lobe and cortical gray matter maturation differently in boys than girls matched for sexual maturity. Cereb Cortex. 2011 Mar;21(3):636-46.

Cançado RH. Estudo comparativo da cronologia de erupção dos dentes permanentes e da calcificação dos segundos molares nas más oclusões de Classe I e Classe II de Angle (Dissertação) Bauru: Universidade de São Paulo, Faculdade de Odontologia de Bauru; 2003.

Candeiro GTM, Correia FC, Candeiro SALM. Ulectomy as surgical option in cases of delay in dental eruption: case report. Revista Odontológica de Araçatuba. 2009; 30(2):45-49. 
Cerri PS, Pereira-Júnior JA, Biselli NB, Sasso-Cerri E. Mast cells and MMP9 in the lamina própria during eruption of rat molars: quantitative and immunohistochemical evulation. J Anat. 2010 Aug; 217(2): 116-125.

Chasman D, Adams RM. Predicting the functional consequences of non-synonymous single nucleotide polymorphisms: structure-based assessment of amino acid variation. J Mol Biol. 2001 Mar; 23;307(2):683-706.

Cole TJ, Bellizzi MC, Flegal KM, Dietz WH. Establishing a standard definition for child overweight and obesity worldwide: international survey. BMJ . 2000;320(7244):12403.

Cordeiro RCL, Gonçalves MA, Pinto LAMS, Estigarribia CCG. Estágios de calcificação e erupção dos dentes permanentes de crianças da zona rural de Araraquara/SP. J. Bras. Ortodon. Ortop. Facial. 2000 mar-abr; 5(26):47-53.

Costa DP, Mota ACM, Bruno GB, Almeida MEL, Fonteles CRS. Protein-energy malnutrition and early childhood caries. Rev. Nutr. 2010 Jan-fev; 23(1):119-126.

Costacurta M, Sicuro L, Di Renzo L, Condò R, De Lorenzo A, Docimo R. Childhood obesity and skeletal-dental maturity. Eur J Paediatr Dent. 2012; 13(2): 128-32.

Delaissé JM, Engsig MT, Everts V, del Carmen Ovejero M, Ferreras $M$, et al. Proteinases in bone resorption: obvious and less obvious roles. Clin Chim Acta. 2000 Feb; 15;291(2):223-34.

Diamanti J, Townsend GC. New standards for permanent tooth emergence in Australian children. Aust Dent J . 2003 Mar; 48(1):39-429.

Duplessis EA, Araujo EA, Behrents RG, Kim KB. Relationship between body mass and dental and skeletal development in children and adolescents. Am J Orthod Dentofacial Orthop. 2016 Aug; 150(2):268-73.

Eskeli R, Lösönen M, Ikävalko T, Myllykangas R, Lakka T, Laine-Alava MT. Secular trends affect timing of emergence of permanent teeth. Angle Orthod. 2016 Jan;86(1):53-8.

Everts V, Delaissé J M, Korper W, Niehof A, Vaes G, Beertsen W. Degradation of collagen in the bone-resorbing compartment underlying the osteoclast involves both cysteine-proteinases and matrix metalloproteinases. J Cell Physiol. 1992 Feb; 150(2):221-31.

Fatemifar G, Evans DM, Tobias JH. The association between primary tooth emergence and anthropometric measures in young adults: findings from a large prospective cohort study. PLoS One. 2014 May; 9(5):96-355.

Fonseca MA. Malnutrition and Oral Health in Children. Current Oral Health Reports. 2017 J une; 4(2):92-96. 
Gan X, B Wong, Wright SD, Cai TQ. Produção de matriz metaloproteinase-9 em Caco-2 de células, em resposta a estímulos inflamatórios. J Interferon Cytokine Res. 2001 Feb; 21 (2):93-8.

Gross J, Lapièrre CM. Collagenolytic activity in amphibian tissues: a tissue culture assay. Proc Natl Acad Sci. 1962 J un; 48(6): 1014-1022.

Guedes-Pinto AC. Odontopediatria. 7 ạ ed. São Paulo (SP): Santos; 2010.

Hanemaaijer R, Sorsa T, Konttinen YT, Ding Y, Sutinen M, Visser H, Van Hinsbergh WW, Helaakoski T, Kainulainen T, Rönkä $H$, Tschesche $H$, Salo T. Matrix metalloproteinase-8 is expressed in rheumatoid synovial fibroblasts and endothelial cells. Regulation by tumor necrosis factor-alpha and doxycycline. J Biol Chem. 1997 Dec; 12;272(50):31504-9.

Hannas AR, Pereira JC, Granjeiro JM, Tjaderhane L: The role of matrix metalloproteinases in the oral environment. Acta Odontol Scand. 2007 Feb;65(1):113.

Hansen L, Kjaer I. A premaxilla with a supernumerary tooth indicating a developmental region with a variety of dental abnormalities: a report of nine cases. Acta Odontol Scand. 2004 Feb;62(1):30-6.

Hedayati Z, Khalafinejad F. Relationship between body mass index, skeletal maturation and dental development in 6- to 15- year old orthodontic patients in a sample of iranian population. J Dent (Shiraz). 2014 Dec; 15(4):180-186.

Heinrich-Weltzien R, Zorn C. Monse B, Kromeyer-Hauschild K. Relationship between malnutrition and the number of permanent teeth in Filipino 10- to 13-year-olds. Biomed Res Int. 2013; 205-950.

Hilgers KK, Akridge $M$, Scheetz JP, Kinane DE. Childhood obesity and dental development. Pediatr Dent. 2006 J an-Feb; 28(1):18-22.

Hua F, Hang L, Chen Z. Trigger osteoclast formation and activation: molecular treatment strategy of delayed tooth eruption. Med Hypotheses. 2007; 69(6):1222-4.

Instituto Brasileiro de Geografia e Estatística (IBGE). Censo Brasileiro de 2010. Rio de J aneiro, 2010.

J effrey JJ. Interstitial collagenases. In: Matrix metalloproteinases. Parks CW, Mecham RP, editors. San Diego, (CA): Academic Press. 1998; 15-42.

Khan N. Eruption time of permanent teeth in pakistani children. Iran J Public Health. 2011; 40(4):63-73.

Kessenbrock K, Plaks V, Werb Z. Matrix metalloproteinases: Regulators of the tumor microenvironment. Cell. 2010 Apr 2;141(1):52-67. 
Kjaer I. Mechanism of human tooth eruption: review article including a new theory for future studies on the eruption process. Scientifica. 2014; 341-905.

Küchler EC, Tannure PN, Falagan-Lotsch P, Lopes TS, Granjeiro JM, Amorim LMF. Buccal cells DNA extraction to obtain high quality human genomic DNA suitable for polymorphism genotyping by PCR-RFLP and Real-Time PCR. J Appl Oral Sci. 2012 Jul-Aug; 20(4): 467-471.

Lakshmappa A, Guledgud MV, Patil K. Eruption times and patterns of permanent teeth in school children of India. Indian J Dent Res. 2011 Nov-Dec; 22(6):755-63.

Leroy R, Bogaerts K, Lesaffre E, Declerck D. The emergence of permanent teeth in Flemish children. Community Dent Oral Epidemiol. 2003 Feb; 31(1):30-9.

Linsuwanont B, Takagi Y, Ohya K, Shimokawa H. Localization of cathepsin K in bovine odontoclasts during deciduous tooth resorption. Calcif Tissue Int. 2002 Feb; 70(2):127-33.

Mackkb, Phillips C, Jain N, Koroluk LD. Relationship between body mass index percentile and skeletal maturation and dental development in orthodontic patients. AmJ Orthod Dentofacial Orthop. 2013 Feb; 143(2):228-34.

Marceau K, Ram N, Houts RM, Grimm KJ, Susman EJ. Individual differences in boys' and girls' timing and tempo of puberty: modeling development with nonlinear growth models. Dev Psychol. 2011 Sep;47(5):1389-409.

Maciejczyk M, Pietrzykowska A, Zalewska A, Knás M, Daniszewska I. The Significance of Matrix Metalloproteinases in Oral Diseases. Adv Clin Exp Med. 2016 MarApr;25(2):383-90.

Marks SC JR, Schroeder HE. Tooth eruption: Theories and facts. Anat Rec. 1996 Jun;245(2):374-93.

Marques GD, et al. Estudos da cronologia de erupção dos dentes permanentes em crianças da cidade de São Paulo. Rev Fac Odontologia USP, 1978;16(2):177-86.

Maruya $\mathrm{Y}$, Sasano $\mathrm{Y}$, Takahashi I, kagayama M, Mayanagi $\mathrm{H}$. Expression of extracellular matrix molecules, MMPs and TIMPs in alveolar bone, cementum and periodontal ligaments during rat tooth eruption. J Electron Microsc. 2003;52(6):593-604.

Moslemi M. An epidemiological survey of the time and sequence of eruption of permanent teeth in 4-15-year-olds in Tehran, Iran. Int J Paediatr Dent. 2004 Nov; 14(6):432-8.

Must A, Phillips SM, Tybor DJ, Lividini K, Hayes C. The association between childhood obesity and tooth eruption. Obesity Silver Spring. 2012 Oct; 20(10):2070-4. 
Navarro V, Nelson Filho P, Silva L, Freitas A. A participação das metaloproteinases da matriz nos processos fisiopatológicos da cavidade bucal. Revista de Odontologia da UNESP. 2006; 35(4): 233-238.

Neves LS. Estudo comparativo da maturação e erupção dos dentes permanentes em jovens com padrões de crescimento vertical e horizontal (Dissertação).Bauru: Universidade de São Paulo, Faculdade de Odontologia de Bauru; 2003.

Oziegbe EO, Temitope AE, Titus AO. Brief communication: emergence chronology of permanent teeth in Nigerian children. Am J Phys Anthropol. 2014 Mar;153(3):50611.

Palosaari $\mathrm{H}$, Wahlgren J, Larmas M, Rönkä $H$, Sorsa $T$, Salo $T$, Tjäderhane L. The expression of MMP-8 in human odontoblasts and dental pulp cells is down-regulated by TGF-betal. J Dent Res. 2000 Jan; 79(1):77-84.

Papaléo Netto M. Gerontologia. São Paulo (SP): Atheneu, 2005.

Parks WC, Wilson CL, Lopez-Boado YS. Matrix metalloproteinases as modulators of inflammation and innate immunity. Nat Rev Immunol. 2004 Aug;4(8):617-29.

Psoter W, Gebrian B, Prophete S, Reid B, Katz R. Effect of early childhood malnutrition on tooth eruption in Haitian adolescents. Community Dent Oral Epidemiol. 2008 Apr; 36(2): 179-89.

Raberin M, Diesmusch C, Cordier MP, Farges JC. Innovations in diagnosis and treatment about a case of primary failure eruption linked to a PTHR1 gene mutation. Orthod Fr. 2015 Sep;86(3):221-31.

Ranade K, Chang MS, Ting CT, et al. High-throughput genotyping with single nucleotide polymorphisms. Genome Res. 2001 Jul; 11(7): 1262-8.

Room W, Monterrey J, Kalinovsky T, Rath M, Niedzwiecki A. Patterns of MMP-2 and MMP-9 expression in human cancer cell lines. Oncol Rep. 2009 May;21(5):1323-33.

Sánchez-Pérez L, Irigoyen ME, Zepeda M. Dental caries, tooth eruption timing and obesity: a longitudinal study in a group of Mexican schoolchildren. Acta Odontol Scand. 2010 Jan; 68(1):57-64.

Sasano Y, Zhu JX, Tsubota M, Takahashi I, Onodera K, Mizoguchi I, Kagayama M. Gene expression of MMP8 and MMP13 during embryonic development of bone and cartilage in the rat mandible and hind limb.J Histochem Cytochem. 2002 Mar;50(3):325-32.

Shastry BS. SNPs and haplotypes: genetic markers for disease and drug response (review). Int J Mol Med. 2003 Mar; 11(3):379-82. 
Sheetal A, Hiremath VK, Patil AG, Sajjansetty S, Kumar SR. Malnutrition and its oral outcome - a review. J Clin Diagn Res. 2013 Jan; 7(1):178-80.

Shiyan H, Nanquan R, Shuhao X, Xiaobing L. Research progress on the cellular and molecular mechanisms of tooth eruption. Hua Xi Kou Qiang Yi Xue Za Zhi. 2016 Jun;34(3):317-21.

Silva LAB, Nelson-Filho P, Espinoza EV, Lucisano MP, editores. Adecuación del medio bucal. Tratado de Odontopediatria. $2^{\mathrm{a}}$ ed. Caracas (Amolca), 2018.

Silver D, Tinker R, Montell D. A new locus required for gurken RNA localization, courgette. A Dros Res Conf. 1998; 39:740C.

Sorsa T, Tjaderhane L, Konttinen YT, Lauhio A, et al. Matrix metalloproteinases: contribution to pathogenesis, diagnosis and treatment of periodontal inflammation. Ann Med. 2006;38(5):306-21.

Tschesche H, Pieper M. Neutrophil collagenase. Barrett AI, Rawlings ND, Woessner JF, editors. Handbook of proteolytic enzymes. Academis, San Diego. 1998;11621167.

Tsubota M, Sasano Y, Takahashi I, Kagayama M, Shimauchi H. Expression of MMP-8 and MMP-13 mRNAs in rat periodontium during tooth eruption. J Dent Res. 2002 Oct;81(10):673-8.

Vantine FF, Carvalho PL, Candelária FLA. Estudo dos fatores que alteram a cronologia de erupção dentária. Rev Virt Odontol. 2007;1(3):18-23.

Visse R, Nagase H. Matrix Metalloproteinases and tissue inhibitors of metalloproteinases: structure, function and biochemistry. Circ Res. 2003 May 2;92(8):827-39.

Who Multicentre Growth Reference Study Group. Who Child Growth Standards: Length/height-for-age. Acta Paediatrica. 2006;450: 76.

Woessner JF, Nagase $\mathrm{H}$, editores. Matrix Metalloproteinases and TIMPs. Oxford: Oxford University Press, 2000.

Zollner MSAC. Estudo sobre o início da cronologia de erupção dentária decídua em crianças desnutridas de Taubaté-SP (Dissertação). Taubaté: Universidade de Taubaté - Departamento de Patologia Geral Departamento de Patologia Geral; 1991. 


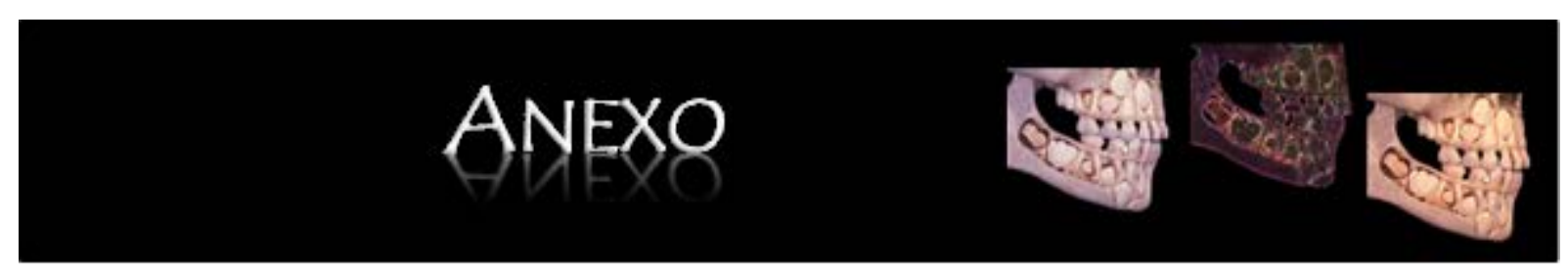





\section{ANEXO}

\section{Anexo A - Parecer Consubstanciado do Comitê de Ética em Pesquisa}

\section{UEA UNIVEASIDAOE DO ESTADO DO A M A ZONAS \\ UNIVERSIDADE DO ESTADO Plotoforma DO AMAZONAS - UEA}

\section{PARECER CONSUBSTANCIADO DO CEP}

\section{DADOS DO PROJETO DE PESQUISA}

Título da Pesquisa: Estudo da doença cárie e das alteraçōes do desenvolvimento do esmalte em crianças atendidas na cidade de Manaus

Pesquisador: ANDRE LUIZ TANNUS DUTRA

Área Temática: Genética Humana:

(Trata-se de pesquisa envolvendo Genética Humana que nẫo necessita de analise ética por parte da CONEP:):

Versăo: 1

CAAE: 39129614.3 .0000 .5016

Instituiçăo Proponente: UNIVERSIDADE DO ESTADO DO AMAZONAS

Patrocinador Principal: Financiamento Próprio

\section{DADOS DO PARECER}

Número do Parecer: 923.569

Data da Relatoria: $11 / 12 / 2014$

\section{Apresentaçẫo do Projeto:}

A doença cárie compromete a saúde e a qualidade de vida de crianças e adultos. Essa doença é um problema de saúde pública mundial.

principalmente nos paises em desenvolvimento, como o Brasil. As alteraçőes do desenvolvimento do esmalte sâo anomalias comuns e estão

associadas ao maior risco de desenvolver lesōes cariosas, bem como, podem representar marcadores clinicos para alteraçóes sistêmicas. Tanto a

cárie, quanto as alteraçōes do desenvolvimento do esmalte sâo alteraçðes de etiologia complexa. Desta forma, o objetivo do presente trabalho é

estudar os fatores etiológicos envolvidos com a etiologia da doença cárie, das alteraçôes de esmalte, bem como avaliar a associaçåo com outras

alteraçôes sistêmicas. A amostra constituirá de 1000 participantes atendidos na Policlinica Odontológica da Escola Superior de Ciências da Saûde

da Universidade do Estado do Amazonas, com idade entre 0 e 14 anos. Para todos os participantes serâo preenchidas fichas com informaços referentes à anamnese e ao exame clinico, para avaliaçâo dos parâmetros clinicos, sócio-

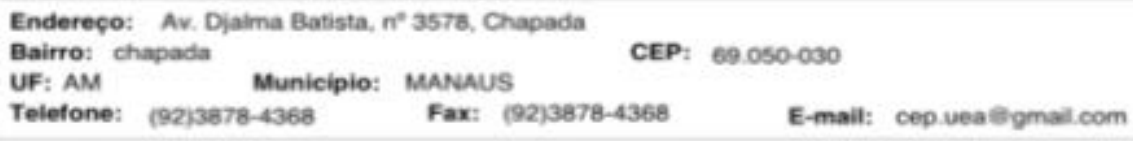




\section{UEA UNIVERSIDADE DO ESTADO DO \\ UNIVERSIDADE DO ESTADO DO AMAZONAS - UEA \\ A M AZONAS}

Continuação do Parecer: 923.569

demográficos e ambientais. Amostras de saliva serão

coletadas como fonte de DNA genômico. A genotipagem será realizada por PCR em Tempo Real. Os dados serão tabulados e analisados em um

programa estatístico com alfa de $5 \%$.

\section{Objetivo da Pesquisa:}

Objetivo Primário:

Avaliar a associação da doença cárie e das alterações do desenvolvimento do esmalte com polimorfismos genéticos, fatores ambientais e sistêmicos

nas crianças atendidas na Policlínica Odontológica da Escola Superior de Ciências da Saúde da Universidade do Estado do Amazonas.

Objetivo Secundário:

1. Avaliar a prevalência da doença cárie em crianças atendidas na Policlínica Odontológica da Escola Superior de Ciências da Saúde da

Universidade do Estado do Amazonas. 2. Avaliar a prevalência das alteraçōes do desenvolvimento do esmalte em crianças atendidas na Policlínica

Odontológica da Escola Superior de Ciências da Saúde da Universidade do Estado do Amazonas. 3. Identificar os fatores ambientais envolvidos

com cárie dentária nessa população. 4. Identificar os fatores ambientais envolvidos com alterações do desenvolvimento do esmalte nessa

população. 5. Verificar se existe associação entre as alterações sistêmicas e do desenvolvimento do esmalte com a doença cárie. 6. Verificar

aexistência de associações entre polimorfismos nos genes envolvidos no sistema imunológico, no desenvolvimento do esmalte e na função de

glåndulas salivares com a doença cárie.7. Verificar a existência de associaçōes entre polimorfismos nos genes envolvidos no sistema imunológico e

no desenvolvimento do esmalte com as alteraçōes do desenvolvimento do esmalte. 8. Verificar a existência de interaçōes genes/genes e

gene/ambiente.9. Verificar se genes candidatos à doença cárie e às alterações do desenvolvimento dentário tem funçăo pleiotrópica com alterações

sistêmicas.

Avaliação dos Riscos e Benefícios:

Riscos:

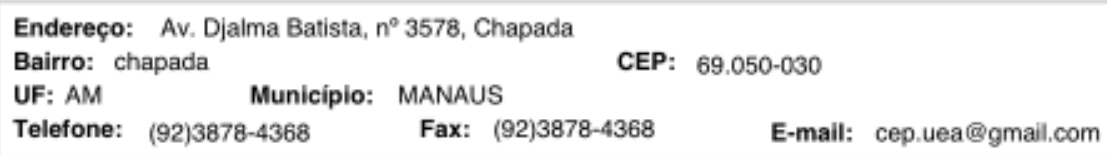




\section{UEA \\ UNIVEASIDADE \\ DO ESTADO DO \\ UNIVERSIDADE DO ESTADO DO AMAZONAS - UEA \\ pesterame AMAZONAS}

Continuagào do Parecer: 923.569

O presente projeto năo apresenta riscos por năo apresentar procedimentos invasivos. Apenas um questionário, bochecho com solução físiológica $e$ medidas de peso e altura serão utilizados com os pacientes.

Beneficios:

A investigaçăo proposta contribuirá para o conhecimento da etiologia e a prevençăo da carie dentária, bem como sua associaçāo com alteraçōes do

desenvolvimento do esmalte e alteraçōes sistêmicas.

Comentários e Consideraçōes sobre a Pesquisa:

Projeto relevante para a prevenção e o tratamento odontopediátrico de crianças portadoras de cárie $e$ alteraçōes no esmalte dentário.

Consideraçōes sobre os Termos de apresentação obrigatória:

Todos os termos foram depositados na Plataforma Brasil.

Recomendaçōes:

Sem recomendaçōes.

Conclusōes ou Pendências e Lista de Inadequaçōes:

Sem pendências.

Situação do Parecer:

Aprovado

Necessita Apreciação da CONEP:

Năo

Consideraçōes Finais a critério do CEP:

Aprovado.

MANAUS, 19 de Dezembro de 2014

Assinado por:

Manoel Luiz Neto

(Coordenador)

Endereço: Av. Djalma Batista, $n^{0} 3578$, Chapada

Bairro: chapada

UF: AM Municipio: MANAUS

Telefone: (92)3878-4368 Fax: $(92) 3878-4368 \quad$ E-mail: cep.uea@gmail.com 



\section{APÊNPICES}





\section{APÊNDICES}

\section{Apêndice A - Carta De Informacão Ao Participante Da Pesquisa}

Título do Projeto de Pesquisa: " Estudo da etiologia das patologias e alterações orais de crianças e adolescentes"

Responsáveis pela pesquisa: Pós-graduandas Silvane e Silva Evangelista e Kátia Regina Felizardo Vasconcelos, Prof. Dr. Léa Assed Bezerra da Silva, Prof. Dr. Paulo Nelson Filho, Prof. Dr. Alexandra Mussolino de Queiroz e Prof. Dr. Érika Calvano Kuchler.

Objetivos da Pesquisa: A presente pesquisa tem como objetivo estudar os fatores etiológicos envolvidos com erupção dentária, bem como avaliar a associação com outras alterações sistêmicas.

J ustificativa: Os genes específicos que influenciam a erupção dentária são desconhecidos. Há poucos estudos específicos sobre a etiologia genética da erupção dentária, bem como sua associação com anomalias sistêmicas.

\section{Procedimentos que serão realizados durante a pesquisa:}

Procedimentos Preliminares - Durante a anamnese serão coletados dados sóciodemográficos, ambientais e culturais do participante da pesquisa e seu cuidador/responsável. Informações referentes aos hábitos de higiene bucal (escovação dentária, uso de fio dental), uso/exposição a fluoretos (uso de dentifrício fluoretado e uso de enxaguatório bucal com flúor) e dieta também serão coletados. Protocolo Clínico: Será realizado exame clínico sob luz artificial, utilizando-se espelho bucal plano no 5 e sonda exploradora. Em seguida, as medidas de comprimento e peso serão realizadas. As amostras de saliva serão coletadas como fonte de DNA. Os participantes realizarão um bochecho com $5 \mathrm{~mL}$ de solução salina durante 1 minuto. Todo o volume do bochecho será acondicionado em tubos para centrífuga de $15 \mathrm{~mL}$ e mantido a $-20^{\circ} \mathrm{C}$. O material coletado será processado, armazenado e analisado no Laboratório de Biologia Molecular do Departamento de Clínica Infantil da Faculdade de Odontologia de Ribeirão Preto.

Desconforto, riscos e benefícios esperados: O presente projeto não apresenta riscos por não apresentar procedimentos invasivos. Apenas um questionário, bochecho com solução fisiológica e medidas de peso e altura serão utilizados com os participantes. Por outro lado, a investigação proposta contribuirá para o conhecimento da etiologia e a prevenção da carie dentária, bem como sua associação com alterações do desenvolvimento do esmalte, alterações sistêmicas e antropométricas.

Acompanhamento e assistência: Todos os procedimentos serão acompanhados pelos pesquisadores. Além disso, os mesmos oferecerão a assistência necessária durante a pesquisa, se o participante da pesquisa tiver algum problema relacionado aos tratamentos.

Garantia de esclarecimentos: Os responsáveis legais pelos participantes têm a garantia de que receberão respostas a qualquer pergunta e esclarecimentos de qualquer dúvida antes, durante e após a realização da pesquisa. Ao convidado a participar da pesquisa, será 
preservado o direito de informação sobre a pesquisa e aos procedimentos aos quais será submetido, no limite de sua capacidade de compreensão. Qualquer problema relacionado à pesquisa deverá ser comunicado o mais breve possível à Silvane e Silva Evangelista pelo telefone (92) 991365328 ou (92) 36114055.

Retirada do consentimento: Os responsáveis legais pelos participantes da pesquisa têm a liberdade de retirar seu consentimento a qualquer momento, não sendo permitida a continuação da pesquisa sem que isso acarrete qualquer penalidade nem represálias de qualquer natureza.

Ressarcimento ou indenização: Há garantia de indenizações, caso ocorram danos diretos ou indiretos, imediatos ou tardios sofridos no decorrer da participação do participante. Os pesquisadores se comprometem a prestar assistência sendo os participantes da pesquisa acompanhados e tratados pelo pesquisador mesmo que não seja estabelecida, imediatamente, sua relação direta com a pesquisa. Apesar desse estudo oferecer risco mínimo a saúde geral do participante.

Garantia de Sigilo: Será mantido sigilo quanto à identidade de todos os participantes da pesquisa na divulgação e publicação dos dados da pesquisa.

Todas as informações contidas neste documento serão explicadas verbalmente, numa linguagem acessível ao participante da pesquisa e aos responsáveis. 
Apêndice B - Termo de Consentimento Livre e Esclarecido

Termo de Consentimento Livre e Esclarecido

(Resolução 466/2012 - Conselho Nacional de Saúde)

Nós, pós-graduandas Silvane e Silva Evangelista e Kátia Regina Felizardo Vasconcelos, doutoranda da Universidade de São Paulo (FORP/USP), responsável pelo projeto "Estudo da etiologia das patologias e alterações orais de crianças e adolescentes", convido você

participar do referido projeto de pesquisa, que será realizado sob orientação da Profa. Léa Assed Bezerra da Silva, do Prof. Paulo Nelson Filho, da Profa. Alexandra Mussolino de Queiroz e da Profa. Dra. Erika Calvano Kuchler, Faculdade de Odontologia de Ribeirão Preto (FORP/USP). Este termo consta de 2 vias idênticas, que serão assinadas por todos os pesquisadores e por você, participante de pesquisa. Uma via ficará com você e a outra será arquivada pelo pesquisador. Este trabalho tem como objetivo avaliar se a genética associação com alterações orais dos alunos da Escola Municipal Thomás Meirelles, Escola Municipal Paula Frassinetti, Centro Educacional de Tempo Integral Áurea Pinheiro Braga e Escola Estadual de Tempo Integral Gilberto Mestrinho. Para tanto será necessário que seja realizado um exame clínico do paciente e que o mesmo faça um bochecho com soro fisiológico e depois cuspa, nessa saliva que avaliaremos a genética e as alterações orais.

Você e o participante de pesquisa virão ao Consultório Odontológico da Escola Municipal Thomás Meirelles, para realização da pesquisa onde será coletada a saliva no dia da consulta. Você está sendo esclarecido que esta pesquisa pode oferecer incômodos, como desconforto ao cuspir e aumento de permanência na Escola no dia da consulta ao dentista.

Os participantes da pesquisa não terão ganhos diretos com os resultados da mesma, mas terão como benefício orientação sobre técnica de higiene bucal, limpeza. A participação de vocês nesta pesquisa é muito importante, pois os resultados encontrados poderão trazer vários benefícios à ciência e ajudar outras pessoas. Não será oferecido nenhum tipo de pagamento pela participação de vocês na pesquisa, sendo que, todo o atendimento ao participante de pesquisa será gratuito. A sua identidade, bem como a do participante de pesquisa serão mantidos em segredo, mas participando da pesquisa você autoriza que os resultados obtidos sejam divulgados e publicados em revistas cientificas e terá, por parte dos pesquisadores, a garantia do sigilo (segredo) que garantem a privacidade de vocês.

Você terá total liberdade para pedir maiores esclarecimentos antes e durante o desenvolvimento da pesquisa.

Se tiver alguma dúvida poderá ligar para o pesquisador para pedir qualquer informação (Silvane e Silva Evangelista - Rua Bernardo Michiles, n.15, Petrópolis- Escola Municipal Thomás Meirelles).

Suas reclamações e/ou insatisfações relacionadas à sua participação na pesquisa poderão ser comunicadas por escrito à secretaria da Faculdade do Amazonas -IAES (92)35846066- Horário de atendimento das $8 \mathrm{~h}$ às $12 \mathrm{~h}$, de segunda a sexta-feira, devendo conter seu nome que será mantido em sigilo.

A participação de vocês não é obrigatória, e vocês poderão desistir a qualquer momento, retirando sua autorização. A não autorização deste trabalho não trará nenhum prejuízo a 
vocês, bem como a sua relação com o pesquisador ou com a Escola Municipal Thomás Meirelles.

Eu

CPF ,residente ,portador RG

\section{a}

número______ na cidade de Manaus, no estado do Amazonas, telefone

Declaro que li, compreendi e concordo com o presente Termo, por isso assino este documento de livre e espontânea vontade.

Manaus, de de 20

\section{Assinatura do responsável legal pelo participante da pesquisa}

PG Silvane e Silva Evangelista

CPF: 708.623.462-15

\section{PG Kátia Regina Felizardo Vasconcelos}

CPF: 314.234.852-20
Profa. Dra. Léa Assed Bezerra da Silva CPF: 741,906.018.53

Pesquisadora orientadora
Prof. Dr. Paulo Nelson Filho

CPF: 156.200.398-46

Pesquisador Responsável
Profa. Dra. Erika Calvano Kuchler CPF: 056.387.897-58

Pesquisadora orientadora
Profa. Dra. Alexandra Mussolino de Queiroz CPF: 062.574.188-95

Pesquisador Responsável 
Apêndice C - Termo de Assentimento

\section{Termo de Assentimento (Resolucão no 466/ 2012 CNS)}

Nós, Pós-graduandas Silvane e Silva Evangelista e Kátia Regina Felizardo Vasconcelos, Prof. Dr. Léa Assed Bezerra da Silva, Prof. Dr. Paulo Nelson Filho, Prof. Dr. Alexandra Mussolino de Queiroz e Prof. Dr. Érika Calvano Kuchler, pesquisadores responsáveis pelo projeto “ Estudo da etiologia das patologias e alteracoes orais de criancas e adolescentes" estamos convidando o (a) participante da pesquisa (a) , sob responsabilidade de , RG: CPF

a participar do desse projeto que será feito na Faculdade de Odontologia de Ribeirão Preto - Universidade de São Paulo.

O objetivo do estudo será:

- Avaliar se o sobrepeso e a obesidade estão associados com o atraso na erupção ou com a cronologia de erupção de dentes permanentes e se as metaloproteinases de matriz (MMPs) estão associadas com o atraso na erupção de dentes permanentes.

- Este trabalho é importante e poderá ser publicado em jornais, revistas e/ou congressos no país e no exterior.

- O bochecho com soro fisiológico não vai prejudicar a saúde do participante da pesquisa.

- Haverá acompanhamento do participante da pesquisa durante toda a pesquisa.

- O participante da pesquisa terá liberdade de não participar da pesquisa, assim como parar de participar, sem que ele seja prejudicado.

- Há garantia de indenizações, caso ocorram danos diretos ou indiretos, imediatos ou tardios sofridos no decorrer da participação da pesquisa. Os pesquisadores se comprometem a prestar assistência, sendo os participantes acompanhados e tratados pelo pesquisador, apesar desse estudo oferecer risco mínimo à saúde geral do participante da pesquisa.

Declaro que fui devidamente esclarecido (a) (de forma oral e escrita) e estou certo de que esta pesquisa tem como pesquisadores responsáveis Prof ${ }^{\circ}$ Dr. Paulo Nelson Filho e Prof $^{a}$. Dra ${ }^{a}$. Érika Calvano KuchlerProf. Dr. Léa Assed Bezerra da Silva, Prof. Dr. Paulo Nelson Filho, Prof. Dr. Alexandra Mussolino de Queiroz e Prof. Dr. Érika Calvano Kuchler.(92) 35846066. Assino este documento de livre e espontânea vontade, estando ciente (certo) do seu conteúdo.

Declaro que li, compreendi e concordo com o presente Termo, por isso assino este documento.

Nome da criança ou adolescente:

Assinatura:

$\overline{\mathrm{PG}}$ Silvane e Silva EvangelistaCPF: 708.623.462-15
PG Kátia Regina Felizardo Vasconcelos CPF: $314.234 .852-20$ 

Profa. Dra. Léa Assed Bezerra da Silva CPF: 741,906.018.53
Pesquisadora orientadora

Prof. Dr. Paulo Nelson Filho

CPF: 156.200.398-46

Pesquisador Responsável
Profa. Dra. Erika Calvano Kuchler CPF: 056.387.897-58

Pesquisadora orientadora
Profa. Dra. Alexandra Mussolino de Queiroz CPF: 062.574.188-95

Pesquisador Responsável CPF:

\section{Assinatura do responsável legal pelo participante da pesquisa} RG:

Nome da criança ou adolescente:

Assinatura: 
Apêndice D - Ficha Clínica

FICHA DE ANAMNESE E EXAME BUCAL

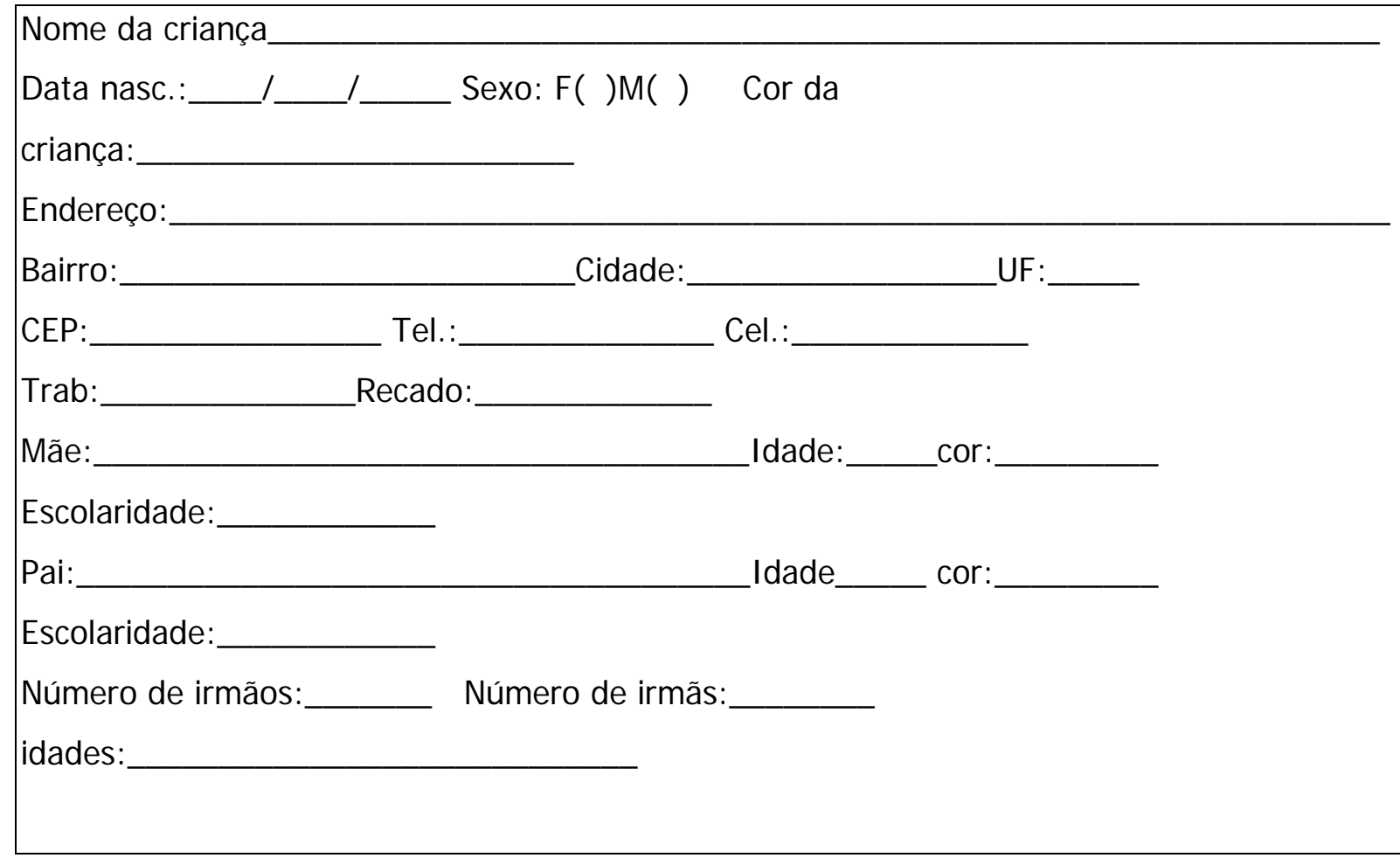

\section{HISTÓRI A MÉDICA}

\section{A MÃE DURANTE A GRAVIDEZ (GESTAÇÃO):}

A mãe durante a gravidez recebeu acompanhamento pré-natal? ( ) Sim ( )Não

a) A mãe durante a gravidez fumou? ( ) Sim ( )Não

b) A mãe durante a gravidez fez uso de Vitaminas? ( )Não ( ) Não Sabe ( )Sim: Quais?

c) A mãe durante a gravidez fez uso de cálcio? ( )Não ( ) Não Sabe ( )Sim: Qual?

d) A mãe durante a gravidez fez uso de algum remédio? ( )Não ( ) Não Sabe

( )Sim: Quais?

A criança tem algum problema de saúde? ( ) Não ( ) Sim:

Qual?

(ex: Asma, bronquite, herpes labial,

A criança já foi ao dentista antes? ( ) Sim ( )Não 


\section{HÁBITOS DE DIETA:}

A criança mamou no peito (Leite materno/amamentação natural)? （ )Sim （ )Não （ ） não sabe Até quando?

Tomou mamadeira?( )Sim （ )Não （） Não sabe

Mamadeira com o que? Até quando?

Consome muito doce entre as refeições? ( )Não ( )Sim

Já usou chupeta? （ Não（ )Sim; Qual a frequência?（ )muito（） mais ou menos（ ） pouco; Até que idade?

Já chupou o dedo?( )Não ( )Sim; Qual a frequência? ( )muito ( ) mais ou menos ( ) pouco; Até que idade?

Já roeu unha? ( )Não ( )Sim; Qual a frequência? ( )muito ( ) mais ou menos ( ) pouco; Até que idade?

Faz algum barulho rangendo os dentes? ( )Não ( )Sim; ( )Durante o dia ( )Durante a noite ( )Dia e noite; Até que idade?

\section{HÁBITOS DE HIGIENE:}

Quem escova o dente do seu filho ( )ele mesmo ( ) responsável (pai, mãe)

( ) tanto a criança quanto o responsável

Quantas vezes a criança escova os dentes por dia?

Escova antes de

dormir? ( )Não ( )Sim

Usa fio dental? ( ) Não （ Sim: （） De vez em quando （ ) Todo dia

\section{USO DE FLUORETOS:}

A pasta de dentes que seu filho usa é: ( ) de adulto ( ) infantil Marca da pasta de dentes:

Seu filho ingere a pasta de dentes? ( )Não （ ) Sim

Seu filho faz bochechos: ( ) não （ ) sim Marca:

Quem prescreveu

\section{EXAME CLÍ NICO:}

Mordida Aberta anterior: ( ) Ausente ( ) Leve ( ) Moderada ( ) Grave Mordida Cruzada posterior( ) Ausente ( ) Unilateral （ ) Bilateral Mordida Cruzada anterior: ( ) Ausente ( ) Presente Quais dentes? 


\begin{tabular}{|c|c|}
\hline \multicolumn{2}{|c|}{ MAXI LA } \\
\hline 17 & 27 \\
\hline 16 & 26 \\
\hline $15 / 55$ & $25 / 65$ \\
\hline $14 / 54$ & $24 / 64$ \\
\hline $13 / 53$ & $23 / 63$ \\
\hline $12 / 52$ & $22 / 62$ \\
\hline $11 / 51$ & $21 / 61$ \\
\hline \multicolumn{2}{|c|}{ MANDÍ BULA } \\
\hline 37 & 47 \\
\hline 36 & 46 \\
\hline $35 / 75$ & $45 / 85$ \\
\hline $34 / 74$ & $44 / 84$ \\
\hline $33 / 73$ & $43 / 83$ \\
\hline $32 / 72$ & $42 / 82$ \\
\hline $31 / 71$ & $41 / 81$ \\
\hline
\end{tabular}

Peso: Altura: 
Apêndice E - Trabalhos Enviados/Aceito para Publicação

Evangelista SS; Vasconcelos KRF; Xavier TA; Oliveira S; Dutra ALT; Nelson-Filho P; Silva LAB; Segato RAB; Queiroz AM; Erika Calvano Küchler EC. TIMING OF PERMANENT TOOTH EMERGENCE IS ASSOCIATED WITH OVERWEIGHT AND OBESE CHI LDREN FROM THE BRAZI LI AN AMAZON REGI ON. Brazilian Dental J ournal. Manuscript I D: BDJ -2018-2230 (artigo aceito para publicação).

Evangelista SS; Vasconcelos KRF; Arid J; Dutra ALT; Oliveira S; Nelson-Filho P; VIEIRA AR; Queiroz AM; Küchler EC. EVALUATI ON OF THE ASSOCI ATI ON METALOPROTEI NASES OF THE MATRIX WITH CHRONOLOGY OF DENTAL ERUPTI ON IN CHILDREN FROM MANAUS- (artigo em fase de redação final).

Arid J; Xavier, TA; Silva RAB; Rossi A; Silva LAB; Queiroz AM; Galo R;Antunes LAA; Evangelista SS; Silva MJ B; Abbasoglu Z; Antunes LS; Nelson-Filho P; Yasuvo SF; Küchler EC. GENETIC POLYMORPHISM IN RANKL IS ASSOCIATED WITH DELAYED PERMANENT TOOTH EMERGENCE. Clinical Oral Investigations (artigo submetido).

Vasconcelos KRF; Evangelista SS; Segato RAB; Oliveira SS; Dutra ALT; Santos AS; Praxedes ADN; Belém LC; Silva LAB; Nelson-Filho P; Küchler EC. ASSESSI NG THE ASSOCI ATI ON BETWEEN DENTAL CARIES AND NUTRITIONAL STATUS IN CHI LDREN FROM THE BRAZI LI AN AMAZON REGION. International J ournal of Clinical Pediatric Dentistry - Manuscript ID: J PJ 1780211217J CP - (artigo aceito para publicação).

Vasconcelos KRF, Evangelista SS, Arid J, Dutra ALT, Oliveira SS, Vieira AR, Segato RAB, Silva LAB, Kuchler EC, Nelson-Filho P. GENETIC POLYMORPHISM IN MMP13 IS ASSOCIATED WITH DENTAL CARIES AND DEVELOPMENTAL DEFECT OF ENAMEL IN CHI LDREN FROM THE AMAZON REGI ON OF BRAZI L - (artigo submetido).

Arid J; Oliveira DB; Evangelista SS; Vasconcelos KRF; Dutra ALT; Oliveira SS; Queiroz AM; Nelson-Filho P; Vieira AR; Küchler EC. ESTROGEN RECEPTOR ALPHA AND GROWTH HORMONE RECEPTOR AND DEVELOPMENTAL DEFECT OF ENAMEL. International J ournal of Paediatric Dentistry. Manuscript IJ PD-05-18-6765 (artigo aceito para publicação). 
Apêndice F - Trabalhos Aceitos/apresentados em congressos

Evangelista SS; Arid J; Segato RBA; Silva LAB; Antunes LS; Nelson-Filho P; Queiroz AM; Küchler EC. POLI MORFI SMO GENÉTI CO EM RANKL ESTÁ ASSOCI ADO COM ATRASO NA ERUPÇÃO DE DENTES PERMANENTES. Trabalho apresentado na $34^{\circ}$ Reunião da Sociedade Brasileira de Pesquisa Odontológica- SBPqO (3 a 6 de setembro de 2017 - Campinas-SP).

Evangelista SS; Vasconcelos KRF; Arid J; Oliveira SS; Dutra ALT; Queiroz AM; Vieira AR; Küchler EC. ASSOCIAÇÃo ENTRE ATRASO DE ERUPÇÃO DENTÁRIA COM POLIMORFISMOS GENÉTICOS EM MMP8 E MMP13. Trabalho apresentado na forma de painel na $35^{\circ}$ Reunião da Sociedade Brasileira de Pesquisa Odontológica- SBPqO ( 2 a 4 de setembro de 2018 - Campinas-SP).

Vasconcelos KRF; Evangelista SS; Arid J; Dutra ALT; Oliveira SS; Vieira AR; Küchler EC; Nelson-Filho P. ASSOCIAÇÃo ENTRE EXPERIÊNCIA DE CÁRIE DENTÁRIA E DEFEITOS DO DESENVOLVIMENTO DO ESMALTE COM POLIMORFISMOS GENÉTICOS EM MMP8, MMP13 E MMP20. Trabalho apresentado na forma de painel na $35^{\circ}$ Reunião da Sociedade Brasileira de Pesquisa Odontológica- SBPqO ( 2 a 4 de setembro de 2018 - Campinas-SP). 